\title{
A Novel Multiphase Model for Traffic Safety Evaluation: A Case Study of South Africa
}

\author{
Željko Stević $\left(10,{ }^{1}\right.$ Dillip Kumar Das $\left(\mathbb{1},{ }^{2}\right.$ and Miloš Kopić ${ }^{3}$ \\ ${ }^{1}$ Faculty of Transport and Traffic Engineering, University of East Sarajevo, Doboj 74000, Bosnia and Herzegovina \\ ${ }^{2}$ Civil Engineering, School of Engineering, Sustainable Transportation Research Group, University of Kwazulu Natal, \\ Durban 4041, South Africa \\ ${ }^{3}$ Faculty of Technical Sciences, University of Novi Sad, Trg Dositeja Obradovića 6, Novi Sad 21000, Serbia \\ Correspondence should be addressed to Željko Stević; zeljkostevic88@yahoo.com
}

Received 18 February 2021; Revised 31 March 2021; Accepted 6 May 2021; Published 11 June 2021

Academic Editor: Miguel A. Salido

Copyright (c) 2021 Željko Stević et al. This is an open access article distributed under the Creative Commons Attribution License, which permits unrestricted use, distribution, and reproduction in any medium, provided the original work is properly cited.

\begin{abstract}
Identification of key indicators that cause safety challenges and vulnerable roads is crucial for improving traffic safety. This paper, therefore, entails to the development of a novel multiphase multicriteria decision-making (MCDM) model to evaluate the vulnerability of urban roads for traffic safety. This was conducted by using data from 17 important roads of a South African city and combining several methods such as CRiteria Importance through Intercriteria Correlation (CRITIC), data envelopment analysis (DEA), and measurement of alternatives and ranking according to compromise solution (MARCOS). Taking the elements of the DEA method, two new approaches for calculating the weights of criteria, the DEA-1 and DEA-2 models, were formed and integrated with the CRITIC method to obtain the final values of criteria weights. The MARCOS method was applied to evaluate 17 alternatives, for each direction separately. The aim of developing such a model is to use the advantages of obtaining objectivity of criteria weights through linear programming and correlation of values of the collected data. Also, the MARCOS method, as one of the newer and applicable methods, provides additional significance. Extensive sensitivity analyses were conducted to validate the model. The findings suggest that there are a certain number of roads that have a high level of safety for both directions, as well as a group of risky roads, which need traffic improvement measures. Thus, the results indicate that the model is sensitive to various approaches and can prioritize vulnerable roads comprehensively based on which safety measures can be taken.
\end{abstract}

\section{Introduction}

The occurrence of road accidents is a recurring challenge across the world. The problem is more pervasive in the cities of developing countries such as South Africa. The majority of the people in the South African cities live in the sprawling suburbs and usually travel daily to various parts of the cities and towards the city centres to work and for other civic activities. The cities are characterized by the location of important public and commercial activities on the roadsides or close to road intersections and squares and having predominantly mixed land-use systems in and around the central areas. Due to the lack of a significant and efficient public transportation system, the majority of people travel by their individual cars or shared public taxis. Moreover, access roads linking suburban residential areas and arterial roads to provide higher accessibility also create more conflict points on these roads. The combined effect of various landuse, activity, road, and traffic-related challenges makes the urban roads susceptible to the incidence of traffic accidents. The occurrence of higher vehicular traffic accidents has been experienced not only on the principal thoroughfares of the cities but also on the arterial roads and intersections located in the suburban areas. For instance, according to the reports from the police stations of a city, more than $45 \%$ of the accidents that happen in the city are observed on the urban arterial roads that connect different suburbs of the city. However, it is also observed that some of the roads are more prone to accidents than others and need adequate interventions. 
Improvement of road safety and the reduction of vehicular accidents have been considered as a prime focus in the cities. The road and traffic departments and municipalities are undertaking remedial measures such as improving road conditions, providing road pavement marking and signage, improving road traffic management systems such as signals, implementing traffic regulations, creating traffic safety awareness programs, and traffic safety audits. However, with limited resources, it becomes difficult to take up remedial measures on each road across the city, and therefore, prioritization of vulnerable roads and areas of accidents is necessary.

In the context of South African cities, most of the studies are aimed at either establishing the linkage between different road, traffic, environmental or human factors with the occurrence of the accidents on the roads or developing remedial measures to improve road safety. However, identification of vulnerable roads and prioritization of these roads based on road geometry, traffic-related parameters, and their linkage with the occurrence of accidents have been undermined. Moreover, most of the studies that have been conducted were based on the use of conventional statistical methods, and studies by using advanced methods are scarce. Since remedial measures to improve road safety demand prioritization or ranking of vulnerable roads in addition to exploring the causes of the occurrence of accidents, there is a need for robust, advanced, and flexible methods that could accommodate various parameters effectively and offer reliable predictions.

Therefore, the objective of the study is to develop an appropriate and robust method that can evaluate and rank vulnerable roads for the occurrence of vehicular traffic accidents effectively. For this purpose, a novel multiphase model consisting of several methods, CRiteria Importance through Intercriteria Correlation (CRITIC), data envelopment analysis (DEA), and measurement of alternatives and ranking according to compromise solution (MARCOS), was developed by using the data from 17 important arterial roads (U3-minor arterial roads) (COTO, TRH26, 2012) of Bloemfontein city in South Africa. The paper presents a study in the city of Bloemfontein related to traffic safety in 17 different streets. Data for both directions of movement ( $\mathrm{N}$ and S) were collected, and a new integrated multiphase model was developed in order to obtain the most relevant indicators of traffic safety in the city. Six criteria were defined. Five of them represented input parameters in the DEA model, while the sixth criterion represented an output parameter, and the values of criteria weights were determined by developing two new approaches DEA-1 and DEA-2. After that, the values obtained with the CRITIC method were integrated, and the final values of criteria weights were calculated. They show that the number of traffic accidents per $\mathrm{km}$ is the most important factor, which is understandable. After that, implementation of the stated weights of criteria in the MARCOS method for ranking streets has been performed. Fulfilling the seated objective and the creation of an integrated model where the DEA method was used in one innovative way can be manifested as the main contribution of the study.
The rest of the paper is structured in the following manner. A succinct account of the literature concerning the traffic crash prediction models (CPMs), specifically the use of CRITIC, DEA, and MARCOS, and demands for hybrid models are given in the next section. This is followed by the methodology, which offers an account of the research flow for the development of the model and description of the CRITIC, DEA, and MARCOS methods. Case study, data collection, and determination of weights by using CRITIC, DEA-1, and DEA-2 models and final weights by the combination of these models as well as evaluation of alternatives by the use of the MARCOS model are presented in the following section. The next section includes the multiphase sensitivity analysis which was conducted by using a reverse rank matrix, changing criteria weights, and comparing with other MCDM models to validate the developed hybrid model. Finally, the implication of the model in terms of ranking of the streets concerning traffic safety is presented in the conclusion section.

\section{Literature Review}

Many traffic accident prediction models are available and used to estimate the occurrence of the accidents on a road section because of road and traffic-related parameters. These models enable establishing quantitative relations between road and traffic characteristics and traffic accidents, as well as the influence of the application of safety interventions on a road section [1]. These models include both traditional statistical or mathematical methods and advanced models based on artificial intelligence models such as multicriteria decisionmaking models. The conventional assessment methods include relative accident rate analysis, time series analysis, and regression analysis $[2,3]$. These methods face a common challenge-the assessment results disagree due to the often different parameter choice [4]. Similarly, weight evaluation methods such as the analytic hierarchy process (AHP), expert scoring method (Delphi), principal component analysis method, eigenvalue method, and gray correlation method are used. The general problem of these methods is that they do not consider the internal correlation and inconsistency of indicators, and the outcomes obtained are often fairly different from the real ones [5]. Consequently, advanced MCDM models such as DEA, MARCOS, TOPSIS, and CRITIC methods that consider the uncertainties and relationship between qualitative concepts and quantitative concepts, which could assist in justifiable, explainable, and transparent decision-making, are increasingly used [3].

Furthermore, integrated model based on the q-ROULSs and EDAS method [6] and OHS risk assessment model by integrating picture fuzzy sets (PFSs) and alternative queuing method (AQM) [7] were used to evaluate and rank the risk of occupational hazards. In another recent study, association rule mining technique, as well as correlating various attributes to the severity of the accident, has been used to identify accident spots [8]. Apart from these models, although not directly linked to traffic safety or OHS, a new method based on double hierarchy hesitant linguistic term sets (DHHLTSs) and alternative queuing method (AQM) to 
evaluate the satisfaction of the rail transit network under a large group environment was developed recently [9].

Data envelopment analysis (DEA) was used by various scholars for analyzing traffic safety aspects. It has been used to prioritize traffic crash sites [10], examine operational efficiency related to the traffic safety [11], assess the urban safety on urban roads, Runde et al., prioritize road safety needs [12], develop road safety policies, and so on. DEA is able to consider multiple inputs and outputs and does not require a functional form, which relates to inputs and outputs. It can optimize each observation and can compare it against best practice observations. This method is also different from other ranking methods as it can add standard errors of crash modification factor and crash costs in the selecting process, as well as the average values (Sadeghi \& Moghaddam, 2016). However, DEA has certain limitations that include the following: it can only calculate relative efficiency measures; and since it is a nonparametric technique, statistical hypothesis tests are difficult [13]. Also, when the number of inputs and outputs is more than the number of decision-making units, DEA models will not be able to separate DMUs [14]. Consequently, DEA, in recent years, is integrated with other methods such as artificial neural networks [15], analytical hierarchy process [16], analytic network process [17], TOPSIS [13, 18], and fuzzy logic $[15,16]$ to convert the qualitative variables into quantitative equivalences.

The MARCOS method has also been used to evaluate the road infrastructure on a road section to rank the accident risk on road sections. The ability to consider fuzzy reference points through the fuzzy ideal and fuzzy antiideal solution at the very beginning of model formation is a major advantage of this method. Also, the ability to determine the degree of utility concerning both set solutions more precisely, proposing new ways to determine utility functions and their aggregation, and the possibility to handle a large set of criteria and alternatives are the other advantages [19].

The CRITIC model determines the objective weights that are premised on the quantification of two fundamental notions of multicriteria decision-making (MCDM) such as the contrast intensity and the conflicting character of the evaluation criteria [20]. The extraction and exploitation of these two fundamental features which are stored as intrinsic information in the data defining the multicriteria problem benefit the decision-making process. In this method, the objective weights derived incorporate both the contrast intensity of each criterion and the conflict between the criteria. Also, the contrast intensity of the criteria is considered by the standard deviation. The conflict between them is assessed by the correlation coefficient [21]. This method comprehensively measures the objective weight by the contrast intensity and conflict between different indexes, which is argued to be more scientific and reasonable. However, studies on the application of the CRITIC method in traffic safety are scarce.

Each of the models discussed has limitations and advantages, and the performance of each model depends on the information available and parameter selection [3, 4]. As a result, often, the models are used in combination with other relevant models, or in other words, hybrid models are popular. Therefore, in this study, the integration of DEA, MARCOS, and CRITIC models has been made, which is a major contribution to the body of the knowledge in the analysis of road traffic safety.

\section{Methodology}

3.1. A Developed Model for Traffic Safety Evaluation. Figure 1 presents a whole diagram of the research flow which is divided into four main phases that are interdependent. The first and second phase have four steps each. The third phase has seven activities, while the last, fourth phase includes a sensitivity analysis that needs to be performed through seven steps, too.

The model presented in Figure 1 encompasses a complete research flow consisting of a total of 22 activities that are causally related. The first phase is the recognition of the need for research, and the area of traffic safety is always present and important for the study of key indicators that affect output parameters, which relate to the number of traffic accidents. After the need for research in the city of Bloemfontein has been determined, the next step is field exploration and then the formation of a database, sorting the data according to the needs of research. The second phase involves determining adequate criteria based on which the evaluation of alternatives will be performed. Six criteria are defined. Five of them refer to input parameters, and the sixth is the output parameter in DEA. After that, data are sorted for each of 17 streets in which the research was conducted. It is important to note that a double MCDM model has been formed, which includes separate data collection and evaluation of streets for both directions (north and south). The third phase is the creation of a new integrated multicriteria model consisting of several steps. CRITIC [22, 23] and DEA methods were used to determine the weight values of criteria. The DEA model was used to determine the values of the criteria in two ways, which is presented in more detail below. Based on their individual values, averaging was performed, the final values were obtained, and they were included in the MARCOS method [24-26] when evaluating alternatives. The last, fourth phase is the verification of previously obtained results through a multiphase sensitivity analysis. Validity tests refer to the (a) formation of reverse rank matrices in which the worst alternative is eliminated from further calculation, (b) change of criterion weight in a dynamic environment, (c) evaluation of alternatives based on individually obtained values of criteria weights using CRITIC, DEA-1, and DEA- 2 methods; in addition, a scenario in which all criteria have equal significance was created, (d) comparative analysis of the obtained results with five other MCDM methods, (e) calculation of SCC for all ranks obtained by applying different approaches, and (f) calculation of the standard deviation of ranks obtained by applying different approaches. 


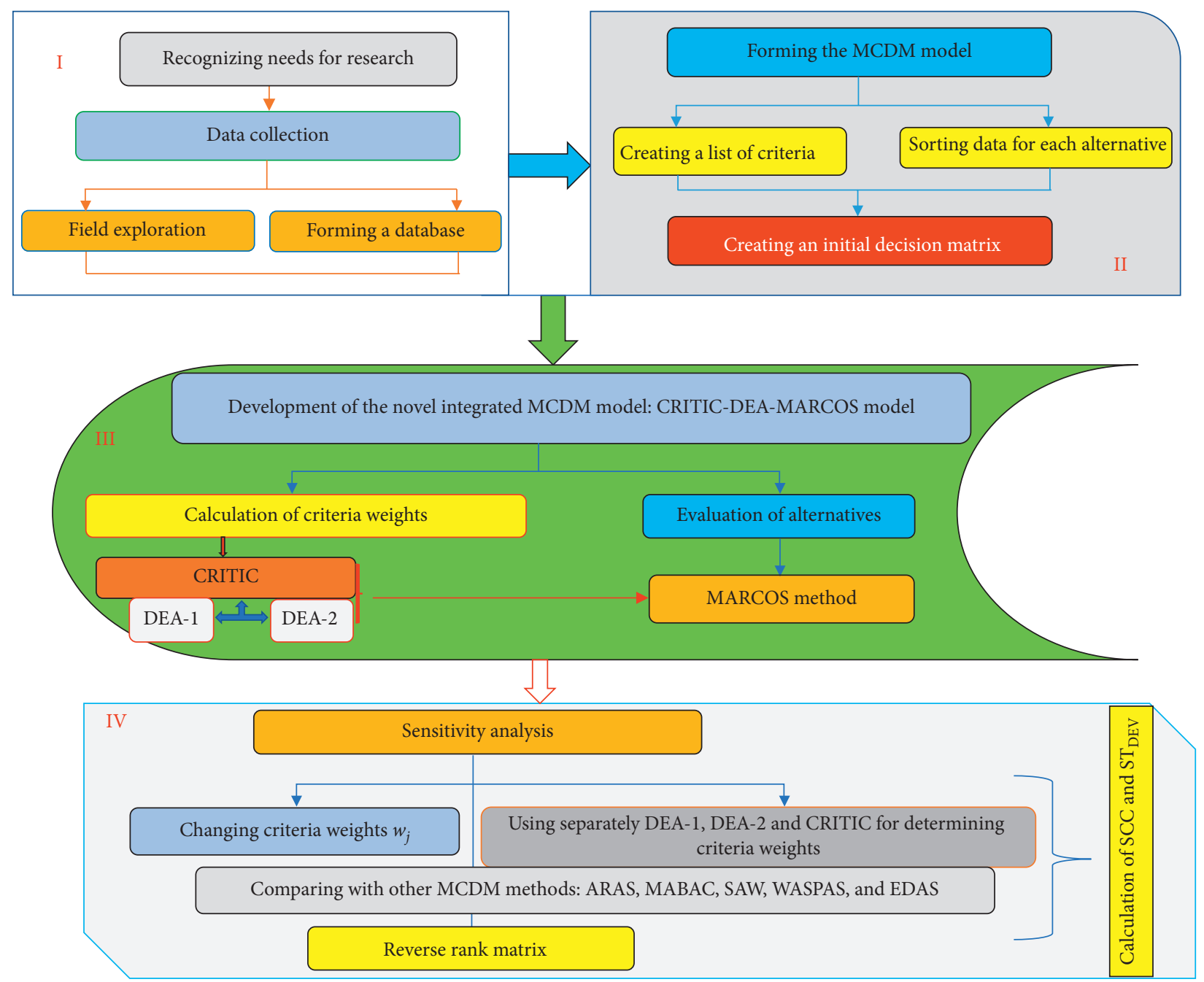

FIGURE 1: Research flow with a developed model for traffic safety evaluation.

3.2. CRITIC Method. Diakoulaki et al. [20] introduced the CRITIC method as a tool for determining the objective weights of criteria in MCDM problems. Steps of this method are presented as follows:

Step 1: formation of the decision matrix $(X)$ :

$$
x_{i j}=\left[\begin{array}{cccc}
x_{11} & x_{12} & \ldots & x_{1 n} \\
x_{21} & x_{22} & \ldots & x_{2 n} \\
\ldots & \ldots & \ldots & \ldots \\
x_{m 1} & x_{m 2} & \ldots & x_{m n}
\end{array}\right], \quad i=1,2, \ldots, m ; j=1,2, \ldots, n .
$$

Step 2: normalization of the initial decision matrix depending on the criterion type:

$$
\begin{aligned}
& r_{i j}=\frac{x_{i j}-\min _{i} x_{i j}}{\max _{i} x_{i j}-\min _{i} x_{i j}} \quad \text { if } j \in B \longrightarrow \max , \\
& r_{i j}=\frac{x_{i j}-\max _{i} x_{i j}}{\min _{i} x_{i j}-\max _{i} x_{i j}} \quad \text { if } j \in C \longrightarrow \min .
\end{aligned}
$$

Step 3: calculation of symmetric linear correlation matrix $r_{i j}$ :

$$
r_{i j}=\frac{n \sum x_{i} y_{i}-\sum x_{i} \sum y_{i}}{\sqrt{n \sum x_{i}^{2}-\left(\sum x_{i}\right)^{2}} \cdot \sqrt{n \sum y_{i}^{2}-\left(\sum y_{i}\right)^{2}}} .
$$

Step 4: determination of objective weights:

$$
W_{j}=\frac{C_{j}}{\sum_{j=1}^{n} C_{j}}, C_{j}=\sigma \sum_{j^{\prime}=1}^{n} 1-r_{i j}, \sum_{j=1}^{n}\left(1-r_{i j}\right), \sigma=\sqrt{\frac{1}{n-1} \sum_{i=1}^{n}\left(x_{i}-\bar{x}\right)^{2}} .
$$


3.3. DEA Method. The DEA-based road safety (DEARS) model proposed by Shen et al. [27] is as follows:

$$
\begin{aligned}
\theta_{o}^{\mathrm{DEA}-\mathrm{RS}} & =\max \sum_{i=1}^{m} w_{i} x_{i o}, \\
\text { st } & \sum_{i=1}^{m} w_{i} x_{i j}-\sum_{i=m+1}^{m+s} w_{i} y_{i j} \leq 0, \quad j=1, \ldots, n, \\
& \sum_{i=m+1}^{m+s} w_{i} y_{i o}=1, \\
w_{i} & \geq 0, \quad i=1, \ldots, m+s .
\end{aligned}
$$

The decision-making unit (DMU) consists of $m$ input parameters, while $s$ represents output parameters taking into account the weights of the parameters denoted by $w_{i}$.

In this paper, the DEA method is applied to calculate the weights of the criteria in one part of the model. In order to be able to accurately determine the weights after obtaining them by applying equation (6), the following two equations (7) and (8) are formed for the DEA-1 model and (9) and (10) for the DEA-2 model:

$$
V_{\mathrm{jDEA}-1}=\frac{\sum_{i=1}^{n} w_{i j}}{n}, \quad j=1, \ldots, m+s,
$$

where $n$ represents the total number of DMUs. In essence, in this equation, all the weights of the criteria are averaged using the arithmetic mean.

After that, the final values according to the DEA-1 model are obtained as follows:

$$
w_{\text {jDEA-1 }}=\frac{V_{j}}{\sum_{j=1}^{m+s} v_{j}},
$$

where $V_{j}$ represents the mean values of weights from the previous equation.

$$
V_{i \mathrm{DEA}-2}=\frac{w_{j}}{\sum_{j=1}^{m+s} w_{j}}
$$

where all individual weights are divided by their sum.

$$
w_{j \mathrm{DEA}-2}=\frac{\sum_{i=1}^{n} V_{i j}}{n}, \quad j=1, \ldots, m+s .
$$

Final values according to the DEA- 2 model are obtained by applying equation (10). In essence, in this equation, all the weights of the criteria are averaged using the arithmetic mean. Also, $n$ represents the total number of DMUs.

3.4. MARCOS Method. The MARCOS method developed by Stević et al. [24] consists of the following steps [28]:

Step 1: formation of an initial decision-making matrix. Step 2: formation of an extended initial matrix. In this step, the extension of the initial matrix is performed by defining the ideal (AI) and anti-ideal (AAI) solution.

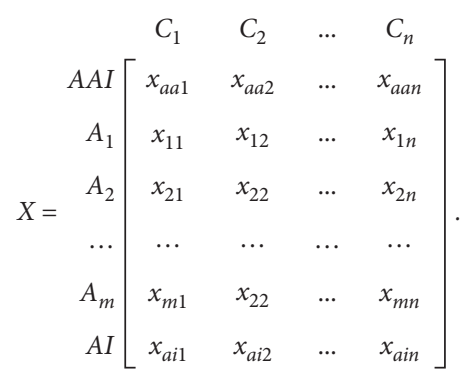

The anti-ideal solution (AAI) is the worst alternative, while the ideal solution (AI) is an alternative with the best characteristic defined by applying equations (12) and (13):

$$
\begin{aligned}
\mathrm{AAI} & =\min _{i} x_{i j} \quad \text { if } j \in B \text { and } \max _{i} x_{i j} \text { if } j \in C, \\
\mathrm{AI} & =\max _{i} x_{i j} \quad \text { if } j \in B \text { and } \min _{i} x_{i j} \text { if } j \in C,
\end{aligned}
$$

where $B$ represents a benefit group of criteria, while $C$ represents a group of cost criteria.

Step 3: normalization of the extended initial matrix $(X)$. The elements of the normalized matrix $N=\left[n_{i j}\right]_{m \times n}$ are obtained by applying equations (14) and (15):

$$
\begin{aligned}
& n_{i j}=\frac{x_{a i}}{x_{i j}} \quad \text { if } j \in C, \\
& n_{i j}=\frac{x_{i j}}{x_{a i}} \quad \text { if } j \in B,
\end{aligned}
$$

where elements $x_{i j}$ and $x_{a i}$ represent the elements of matrix $X$.

Step 4: determination of the weighted matrix $V=\left[v_{i j}\right]_{m \times n}$ :

$$
v_{i j}=n_{i j} \times w_{j} .
$$

Step 5: calculation of the utility degree of alternatives $K_{i}$ by applying equations (17) and (18):

$$
\begin{aligned}
& K_{i}^{-}=\frac{S_{i}}{S_{a a i}}, \\
& K_{i}^{+}=\frac{S_{i}}{S_{a i}},
\end{aligned}
$$

where $S_{i}(i=1,2, \ldots, m)$ represents the sum of the elements of weighted matrix $V$ :

$$
S_{i}=\sum_{i=1}^{n} v_{i j}
$$

Step 6: determination of the utility function of alternatives $f\left(K_{i}\right)$ defined by the following equation: 


$$
f\left(K_{i}\right)=\frac{K_{i}^{+}+K_{i}^{-}}{1+1-f\left(K_{i}^{+}\right) / f\left(K_{i}^{+}\right)+1-f\left(K_{i}^{-}\right) / f\left(K_{i}^{-}\right)},
$$

where $f\left(K_{i}^{-}\right)$represents the utility function in relation to the anti-ideal solution, while $f\left(K_{i}^{+}\right)$represents the utility function in relation to the ideal solution.

Utility functions in relation to the ideal and anti-ideal solution are determined by applying equations (21) and (22):

$$
\begin{aligned}
& f\left(K_{i}^{-}\right)=\frac{K_{i}^{+}}{K_{i}^{+}+K_{i}^{-}}, \\
& f\left(K_{i}^{+}\right)=\frac{K_{i}^{-}}{K_{i}^{+}+K_{i}^{-}} .
\end{aligned}
$$

Step 7: ranking the alternatives. Ranking of the alternatives is premised on the final values of utility functions. It is desirable that an alternative has the highest possible value of the utility function.

\section{Case Study}

The arterial roads of Bloemfontein city in South Africa (Figure 2) were chosen for collecting data for this research. Bloemfontein is a typical middle-sized sprawling city with a population of more than 500,000 and functions as the capital of the Free State province. The majority of the people live in suburban areas, thereby necessitating large-scale intracity vehicular travel.

The city has a hierarchical road system with principal arterials (U1 and U2), minor arterial (U3), collector roads (U4), local streets (U5), and cul-de-sacs (COTO, TRH26, 2012). The road network constitutes a general gridiron and loop pattern and the integration of the two. The U3 roads, which pass through the suburban areas, connect to the U1 and U2 roads of the city. Also, these U3 roads act as the major thoroughfares in the suburban areas offering linkage to the collector roads and the local streets to offer access to the people.

The road surfaces of most of the roads are paved and well maintained. The principal mode of travel in the city is personal/individual-driven motor cars. About $60 \%$ of people travel by their private vehicles for daily commute. However, according to police reports, a significant share (about 45\%) of the total accidents, which occur in and around the city, is observed on these U3 arterial roads. Thus, the importance of the arterial roads (U3) and the high incidence of traffic accidents on these roads of the city warranted this investigation.

4.1. Survey and Data Collection. A survey research method was used to collect data. Data were collected from both primary and secondary sources. Three different types of survey, household surveys, traffic surveys, and road geometrical parameter survey, were made. The household sample survey was conducted among 410 road users (from households located in six important suburbs of the city. The suburbs include Fichardt Park, Pellissier, Universitas, Gradenia Park, Wilgehof, and Langenhoven Park. The suburbs were chosen based on their functional importance, population, vehicle ownership, accessibility, the complexity of the road network, the location of arterial thoroughfares inside the residential area, and the occurrence of the number of accidents. The sample size is adequate $(\geq 384)$ for a population 500,000 at a $95 \%$ confidence level and worst-case percentage of $50 \%$ ). This household survey was conducted to understand the perceptions of road users on the factors that cause accidents on urban roads. A systematic stratified random sampling process was used to conduct the survey. Traffic and road surveys were conducted on important road sections. A traffic survey was conducted at important road sections of the selected $17 \mathrm{U} 3$ roads passing through the selected suburban areas to observe the volume (ADT), speed, and traffic control and management scenarios. The roads selected for this investigation include Jan Spies Street, Totius Street, Wynand Mouton Drive, De Bruyn Street, Paul Kruger Drive North, Paul Kruger Drive South, Volkspele Drive, Pellissier Drive, Paul Kruger Drive (E), Gardenia Avenue, Van Schalkwyk Street, Haldon Drive, Edeling Street, Stals Road, Benade Drive (N), Benade Drive (S), and Eric Rosendorf Street. These U3 roads connect different suburbs and important activity centres of the city. Generally, these roads are flexible paved one-way roads having two or more lanes with or without medians. The junctions of the roads are controlled by automated signalling systems. The traffic survey was conducted uninterruptedly for sixteen hours a day (6.00 am to 22.00 hours) for a week that includes both weekdays and weekends. Similarly, physical road surveys were conducted at important road sections of these roads to assess the current status of the road geometry parameters (road width, shoulder width, lane width, number of lanes, curbs, curvature, median width, gradient, sight distance, and road surface condition) and their influence on the incidence of the accidents. The households' surveys and road and traffic surveys were conducted during the year 2017. The average accident data on different roads over the period 2010 to 2017 were collected from published and unpublished documents and the police station records of the city. The surveys and assessment of the incidence of accidents were conducted on both directions represented by $\mathrm{N}$ and $\mathrm{S}$, indicating the two different ways of these roads.

\subsection{Determining Criteria Weights Using the CRITIC Method.}

Step 1: development of the decision matrix $(X)$ that is shown in Table 1. The initial matrix is shown for both directions since, as already mentioned, the data are different by directions, which means that we practically have two initial matrices.

Step 2: normalization of the initial matrix is shown in Table 2 .

Normalization for cost criteria is performed using equation (2), for example, 


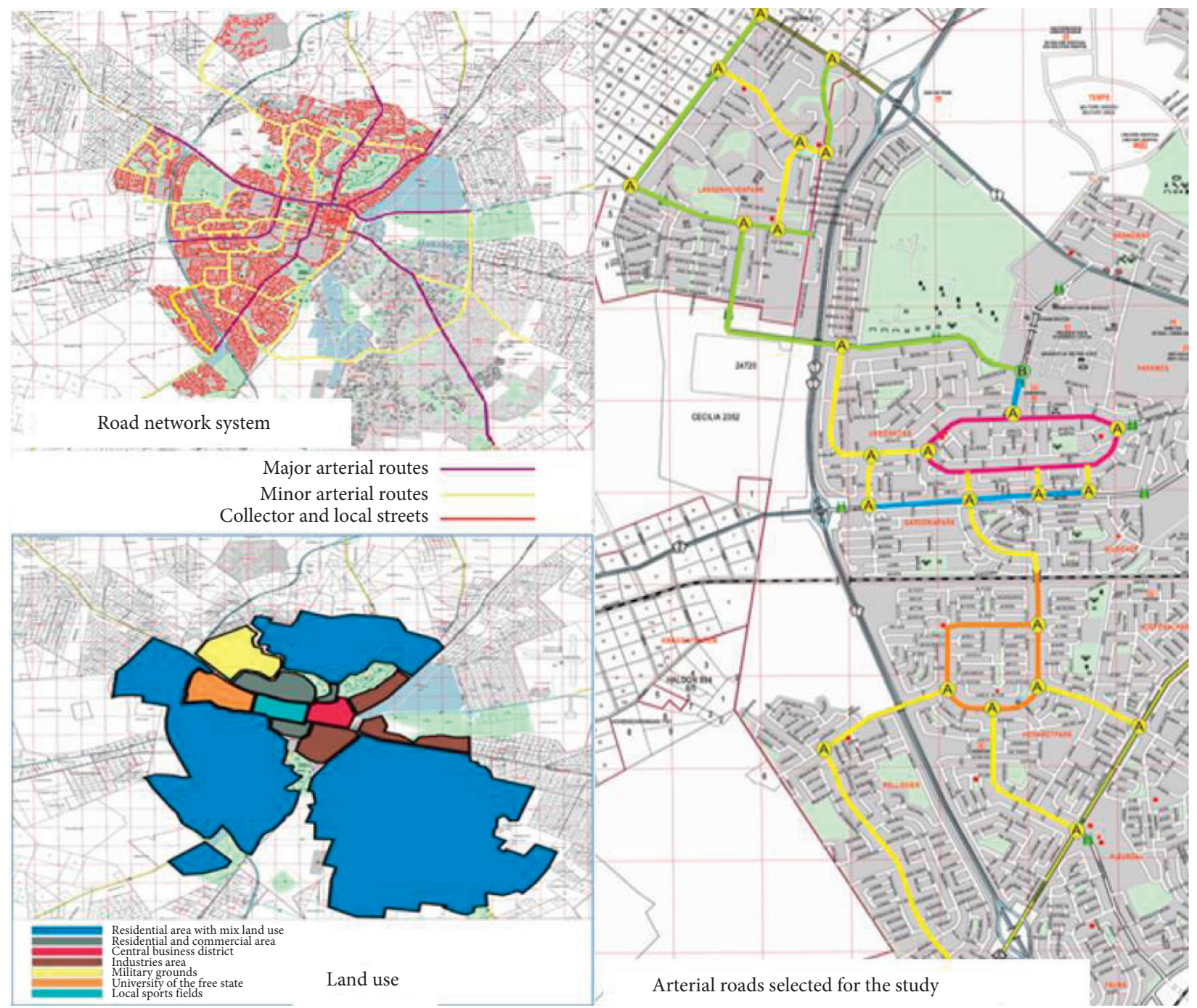

FIGURE 2: Map of the arterial roads selected for the study.

TABLe 1: Initial decision matrix for both directions ( $\mathrm{N}$ and $\mathrm{S}$ ).

\begin{tabular}{lccccccccccccc}
\hline $\mathrm{N}$ & $C_{1}$ & $C_{2}$ & $C_{3}$ & $C_{4}$ & $C_{5}$ & $C_{6}$ & $\mathrm{~S}$ & $C_{1}$ & $C_{2}$ & $C_{3}$ & $C_{4}$ & $C_{5}$ & $C_{6}$ \\
\hline $\mathrm{ST}_{1}$ & 71 & 4611 & 6.2 & 2 & 8 & 16 & $\mathrm{ST}_{1}$ & 69 & 5082 & 6.2 & 2 & 7 & 17 \\
$\mathrm{ST}_{2}$ & 76 & 8908 & 6.5 & 2 & 8 & 25 & $\mathrm{ST}_{2}$ & 73 & 9359 & 6.7 & 2 & 7 & 23 \\
$\mathrm{ST}_{3}$ & 79 & 9938 & 6.1 & 1 & 9 & 32 & $\mathrm{ST}_{3}$ & 75 & 10133 & 6.2 & 1 & 11 & 26 \\
$\mathrm{ST}_{4}$ & 77 & 8888 & 6.0 & 2 & 8 & 13 & $\mathrm{ST}_{4}$ & 74 & 9009 & 6.4 & 2 & 7 & 11 \\
$\mathrm{ST}_{5}$ & 72 & 9285 & 7.5 & 2 & 15 & 32 & $\mathrm{ST}_{5}$ & 70 & 9133 & 7.5 & 2 & 12 & 30 \\
$\mathrm{ST}_{6}$ & 75 & 7409 & 7.0 & 2 & 11 & 21 & $\mathrm{ST}_{6}$ & 74 & 6171 & 7 & 2 & 5 & 15 \\
$\mathrm{ST}_{7}$ & 58 & 6040 & 6.0 & 2 & 4 & 8 & $\mathrm{ST}_{7}$ & 57 & 5929 & 6 & 2 & 3 & 7 \\
$\mathrm{ST}_{8}$ & 71 & 5888 & 7.5 & 2 & 4 & 12 & $\mathrm{ST}_{8}$ & 73 & 4696 & 7.5 & 2 & 4 & 13 \\
$\mathrm{ST}_{9}$ & 73 & 10055 & 6.7 & 2 & 7 & 22 & $\mathrm{ST}_{9}$ & 78 & 11669 & 6.8 & 2 & 9 & 30 \\
$\mathrm{ST}_{10}$ & 74 & 5444 & 6.0 & 2 & 4 & 9 & $\mathrm{ST}_{10}$ & 66 & 5962 & 6 & 2 & 4 & 9 \\
$\mathrm{ST}_{11}$ & 67 & 3227 & 4.3 & 2 & 4 & 7 & $\mathrm{ST}_{11}$ & 74 & 5257 & 4.3 & 2 & 4 & 14 \\
$\mathrm{ST}_{12}$ & 81 & 10016 & 12.0 & 3 & 8 & 33 & $\mathrm{ST}_{12}$ & 74 & 10636 & 12 & 3 & 5 & 31 \\
$\mathrm{ST}_{13}$ & 65 & 7434 & 6.0 & 2 & 4 & 9 & $\mathrm{ST}_{13}$ & 69 & 6980 & 6 & 2 & 5 & 15 \\
$\mathrm{ST}_{14}$ & 67 & 7267 & 6.0 & 2 & 4 & 11 & $\mathrm{ST}_{14}$ & 61 & 7879 & 6 & 2 & 3 \\
$\mathrm{ST}_{15}$ & 75 & 8693 & 9.0 & 2 & 11 & 28 & $\mathrm{ST}_{15}$ & 71 & 8500 & 8.5 & 2 & 9 \\
$\mathrm{ST}_{16}$ & 70 & 7047 & 7.5 & 2 & 7 & 16 & $\mathrm{ST}_{16}$ & 72 & 6654 & 7.5 & 2 & 7 \\
$\mathrm{ST}_{17}$ & 66 & 5029 & 6.0 & 2 & 4 & 9 & $\mathrm{ST}_{17}$ & 61 & 4330 & 6 & 2 & 3 \\
\hline
\end{tabular}


TABLE 2: Normalization of initial decision matrices.

\begin{tabular}{lccccccccccccc}
\hline $\mathrm{N}$ & $C_{1}$ & $C_{2}$ & $C_{3}$ & $C_{4}$ & $C_{5}$ & $C_{6}$ & $\mathrm{~S}$ & $C_{1}$ & $C_{2}$ & $C_{3}$ & $C_{4}$ & $C_{5}$ & $C_{6}$ \\
\hline $\mathrm{ST}_{1}$ & 0.435 & 0.797 & 0.247 & 0.500 & 0.636 & 0.654 & $\mathrm{ST}_{1}$ & 0.429 & 0.898 & 0.247 & 0.500 & 0.556 & 0.538 \\
$\mathrm{ST}_{2}$ & 0.217 & 0.168 & 0.286 & 0.500 & 0.636 & 0.308 & $\mathrm{ST}_{2}$ & 0.238 & 0.315 & 0.312 & 0.500 & 0.556 & 0.308 \\
$\mathrm{ST}_{3}$ & 0.087 & 0.017 & 0.234 & 0.000 & 0.545 & 0.038 & $\mathrm{ST}_{3}$ & 0.143 & 0.209 & 0.247 & 0.000 & 0.111 & 0.192 \\
$\mathrm{ST}_{4}$ & 0.174 & 0.171 & 0.221 & 0.500 & 0.636 & 0.769 & $\mathrm{ST}_{4}$ & 0.190 & 0.362 & 0.273 & 0.500 & 0.556 & 0.769 \\
$\mathrm{ST}_{5}$ & 0.391 & 0.113 & 0.416 & 0.500 & 0.000 & 0.038 & $\mathrm{ST}_{5}$ & 0.381 & 0.346 & 0.416 & 0.500 & 0.000 & 0.038 \\
$\mathrm{ST}_{6}$ & 0.261 & 0.388 & 0.351 & 0.500 & 0.364 & 0.462 & $\mathrm{ST}_{6}$ & 0.190 & 0.749 & 0.351 & 0.500 & 0.778 & 0.615 \\
$\mathrm{ST}_{7}$ & 1.000 & 0.588 & 0.221 & 0.500 & 1.000 & 0.962 & $\mathrm{ST}_{7}$ & 1.000 & 0.782 & 0.221 & 0.500 & 1.000 & 0.923 \\
$\mathrm{ST}_{8}$ & 0.435 & 0.610 & 0.416 & 0.500 & 1.000 & 0.808 & $\mathrm{ST}_{8}$ & 0.238 & 0.950 & 0.416 & 0.500 & 0.889 & 0.692 \\
$\mathrm{ST}_{9}$ & 0.348 & 0.000 & 0.312 & 0.500 & 0.727 & 0.423 & $\mathrm{ST}_{9}$ & 0.000 & 0.000 & 0.325 & 0.500 & 0.333 & 0.038 \\
$\mathrm{ST}_{10}$ & 0.304 & 0.675 & 0.221 & 0.500 & 1.000 & 0.923 & $\mathrm{ST}_{10}$ & 0.571 & 0.778 & 0.221 & 0.500 & 0.889 & 0.846 \\
$\mathrm{ST}_{11}$ & 0.609 & 1.000 & 0.000 & 0.500 & 1.000 & 1.000 & $\mathrm{ST}_{11}$ & 0.190 & 0.874 & 0.000 & 0.500 & 0.889 & 0.654 \\
$\mathrm{ST}_{12}$ & 0.000 & 0.006 & 1.000 & 1.000 & 0.636 & 0.000 & $\mathrm{ST}_{12}$ & 0.190 & 0.141 & 1.000 & 1.000 & 0.778 & 0.000 \\
$\mathrm{ST}_{13}$ & 0.696 & 0.384 & 0.221 & 0.500 & 1.000 & 0.923 & $\mathrm{ST}_{13}$ & 0.429 & 0.639 & 0.221 & 0.500 & 0.778 & 0.615 \\
$\mathrm{ST}_{14}$ & 0.609 & 0.408 & 0.221 & 0.500 & 1.000 & 0.846 & $\mathrm{ST}_{14}$ & 0.810 & 0.516 & 0.221 & 0.500 & 1.000 & 0.923 \\
$\mathrm{ST}_{15}$ & 0.261 & 0.199 & 0.610 & 0.500 & 0.364 & 0.192 & $\mathrm{ST}_{15}$ & 0.333 & 0.432 & 0.545 & 0.500 & 0.333 & 0.346 \\
$\mathrm{ST}_{16}$ & 0.478 & 0.441 & 0.416 & 0.500 & 0.727 & 0.654 & $\mathrm{ST}_{16}$ & 0.286 & 0.683 & 0.416 & 0.500 & 0.556 & 0.462 \\
$\mathrm{ST}_{17}$ & 0.652 & 0.736 & 0.221 & 0.500 & 1.000 & 0.923 & $\mathrm{ST}_{17}$ & 0.810 & 1.000 & 0.221 & 0.500 & 1.000 & 1.000 \\
\hline
\end{tabular}

$x_{N-11}=\frac{71-81}{58-81}=0.435, x_{S-42}=\frac{9009-11669}{4330-11669}=0.362$.

Normalization for benefit criteria is performed using equation (3), for example,

$$
x_{N-13}=\frac{6.2-4.3}{12-4.3}=0.247, x_{S-14}=\frac{2-1}{3-1}=0.500 \text {. }
$$

Step 3: the symmetric linear correlation matrix $\left(m_{i j}\right)$ is shown in Table 3.

Step 4: determination of the objective weights of criteria, shown in Table 4.

After applying all the steps of the CRITIC method and the weighted normalized matrix shown in Table 5, it can be seen that the third criterion, road width $(m)$, is the most significant with a value of 0.220 for the $\mathrm{N}$-direction and a value of 0.204 for the S-direction. It is interesting to note that the sixth criterion, the average number of accidents (per $\mathrm{km}$ ), is the second most significant and has an identical value of 0.187 for both directions. Essentially, the differences in the values of the criteria are not dominant in any case.

4.3. Determining Criteria Weights Using DEA-1 and DEA-2 Models. By applying equation (6), the individual values of the criteria for each DMU are obtained. An example of obtaining the values of criteria for DMU17-N is shown in Appendix. After solving this model shown in Appendix in Lingo 17 software, the following values are obtained: $w_{1}=0.005, w_{2}=0.000, w_{3}=0.095, w_{4}=0.000, w_{5}=0.000$, and $w_{6}=0.111$. It is necessary to form such a model for all 17 DMUs in order to obtain individual values. By solving all 17 models, the weights shown in Table 6 are obtained.

By applying equations (7) and (8), the values of the criteria according to the DEA-1 model are obtained as follows:

$$
\begin{aligned}
& V_{1 \mathrm{DEA}-1}=0.002, V_{2 \mathrm{DEA}-1}=0.000, V_{3 \mathrm{DEA}-1}=0.021, V_{4 \mathrm{DEA}-1}=0.024, V_{5 \mathrm{DEA}-1}=0.034, V_{6 \mathrm{DEA}-1}=0.073, \\
& V_{1 \mathrm{DEA}-1}=\frac{0+0+0+0+0+0+0+0+0+0.007+0.015+0+0+0.007+0+0+0.005}{17}=0.002, \\
& w_{1 \mathrm{DEA}-1}=0.013, w_{2 \mathrm{DEA}-1}=0.000, w_{3 \mathrm{DEA}-1}=0.139, w_{4 \mathrm{DEA}-1}=0.154, V_{5 \mathrm{DEA}-1}=0.221, V_{6 \mathrm{DEA}-1}=0.472, \\
& w_{1 \mathrm{DEA}-1}=\frac{0.002}{0.154}=0.013 .
\end{aligned}
$$


TABLe 3: Symmetric linear correlation matrix.

\begin{tabular}{cccccccccccccc}
\hline $\mathrm{N}$ & $C_{1}$ & $C_{2}$ & $C_{3}$ & $C_{4}$ & $C_{5}$ & $C_{6}$ & $\mathrm{~S}$ & $C_{1}$ & $C_{2}$ & $C_{3}$ & $C_{4}$ & $C_{5}$ & $C_{6}$ \\
\hline$C_{1}$ & 1.000 & 0.612 & -0.516 & -0.062 & 0.550 & 0.727 & $C_{1}$ & 1.000 & 0.497 & -0.279 & 0.031 & 0.547 & 0.690 \\
$C_{2}$ & 0.612 & 1.000 & -0.534 & -0.007 & 0.584 & 0.787 & $C_{2}$ & 0.497 & 1.000 & -0.453 & -0.040 & 0.637 & 0.764 \\
$C_{3}$ & -0.516 & -0.534 & 1.000 & 0.626 & -0.403 & -0.650 & $C_{3}$ & -0.279 & -0.453 & 1.000 & 0.635 & -0.188 & -0.573 \\
$C_{4}$ & -0.062 & -0.007 & 0.626 & 1.000 & 0.055 & -0.019 & $C_{4}$ & 0.031 & -0.040 & 0.635 & 1.000 & 0.380 & -0.104 \\
$C_{5}$ & 0.550 & 0.584 & -0.403 & 0.055 & 1.000 & 0.815 & $C_{5}$ & 0.547 & 0.637 & -0.188 & 0.380 & 1.000 & 0.776 \\
$C_{6}$ & 0.727 & 0.787 & -0.650 & -0.019 & 0.815 & 1.000 & $C_{6}$ & 0.690 & 0.764 & -0.573 & -0.104 & 0.776 & 1.000 \\
\hline
\end{tabular}

TABle 4: Results of applying the CRITIC method.

\begin{tabular}{|c|c|c|c|c|c|c|c|c|c|c|c|c|c|}
\hline$N$ & \multicolumn{6}{|c|}{$1-r_{i j}$} & $S$ & \multicolumn{6}{|c|}{$1-r_{i j}$} \\
\hline$C_{1}$ & 0.000 & 0.388 & 1.516 & 1.062 & 0.450 & 0.273 & $C_{1}$ & 0.000 & 0.503 & 1.279 & 0.969 & 0.453 & 0.310 \\
\hline$C_{2}$ & 0.388 & 0.000 & 1.534 & 1.007 & 0.416 & 0.213 & $C_{2}$ & 0.503 & 0.000 & 1.453 & 1.040 & 0.363 & 0.236 \\
\hline$C_{3}$ & 1.516 & 1.534 & 0.000 & 0.374 & 1.403 & 1.650 & $C_{3}$ & 1.279 & 1.453 & 0.000 & 0.365 & 1.188 & 1.573 \\
\hline$C_{4}$ & 1.062 & 1.007 & 0.374 & 0.000 & 0.945 & 1.019 & $C_{4}$ & 0.969 & 1.040 & 0.365 & 0.000 & 0.620 & 1.104 \\
\hline$C_{5}$ & 0.450 & 0.416 & 1.403 & 0.945 & 0.000 & 0.185 & $C_{5}$ & 0.453 & 0.363 & 1.188 & 0.620 & 0.000 & 0.224 \\
\hline$C_{6}$ & 0.273 & 0.213 & 1.650 & 1.019 & 0.185 & 0.000 & $C_{6}$ & 0.310 & 0.236 & 1.573 & 1.104 & 0.224 & 0.000 \\
\hline $\mathrm{ST}_{\mathrm{DEV}}$ & 0.250 & 0.304 & 0.216 & 0.177 & 0.294 & 0.356 & $\mathrm{ST}_{\mathrm{DEV}}$ & 0.273 & 0.305 & 0.210 & 0.177 & 0.310 & 0.327 \\
\hline$\sum$ & 3.689 & 3.558 & 6.477 & 4.406 & 3.399 & 3.340 & $\sum$ & 3.513 & 3.595 & 5.857 & 4.098 & 2.848 & 3.447 \\
\hline$C_{j}$ & 0.922 & 1.082 & 1.401 & 0.779 & 0.998 & 1.190 & $C_{j}$ & 0.958 & 1.096 & 1.228 & 0.724 & 0.883 & 1.127 \\
\hline$\sum C_{j}$ & \multicolumn{6}{|c|}{6.371} & $\sum C_{j}$ & \multicolumn{6}{|c|}{6.016} \\
\hline$W_{\mathrm{j}}$ & 0.145 & 0.170 & 0.220 & 0.122 & 0.157 & 0.187 & $W_{\mathrm{j}}$ & 0.159 & 0.182 & 0.204 & 0.120 & 0.147 & 0.187 \\
\hline
\end{tabular}

TABLE 5: The weighted normalized matrix.

\begin{tabular}{|c|c|c|c|c|c|c|c|c|c|c|c|c|c|}
\hline $\mathrm{N}$ & $C_{1}$ & $C_{2}$ & $C_{3}$ & $C_{4}$ & $C_{5}$ & $C_{6}$ & $S$ & $C_{1}$ & $C_{2}$ & $C_{3}$ & $C_{4}$ & $\mathrm{C}_{5}$ & $C_{6}$ \\
\hline AAI & 0.041 & 0.018 & 0.060 & 0.037 & 0.058 & 0.083 & AAI & 0.039 & 0.023 & 0.033 & 0.048 & 0.074 & 0.057 \\
\hline $\mathrm{ST}_{1}$ & 0.047 & 0.040 & 0.087 & 0.073 & 0.109 & 0.171 & $\mathrm{ST}_{1}$ & 0.044 & 0.052 & 0.048 & 0.097 & 0.126 & 0.104 \\
\hline $\mathrm{ST}_{2}$ & 0.044 & 0.021 & 0.091 & 0.073 & 0.109 & 0.110 & $\mathrm{ST}_{2}$ & 0.042 & 0.028 & 0.052 & 0.097 & 0.126 & 0.077 \\
\hline $\mathrm{ST}_{3}$ & 0.042 & 0.018 & 0.085 & 0.037 & 0.097 & 0.086 & $\mathrm{ST}_{3}$ & 0.040 & 0.026 & 0.048 & 0.048 & 0.080 & 0.068 \\
\hline $\mathrm{ST}_{4}$ & 0.043 & 0.021 & 0.084 & 0.073 & 0.109 & 0.211 & $\mathrm{ST}_{4}$ & 0.041 & 0.029 & 0.050 & 0.097 & 0.126 & 0.161 \\
\hline $\mathrm{ST}_{5}$ & 0.046 & 0.020 & 0.105 & 0.073 & 0.058 & 0.086 & $\mathrm{ST}_{5}$ & 0.043 & 0.029 & 0.058 & 0.097 & 0.074 & 0.059 \\
\hline $\mathrm{ST}_{6}$ & 0.044 & 0.025 & 0.098 & 0.073 & 0.079 & 0.130 & $\mathrm{ST}_{6}$ & 0.041 & 0.043 & 0.054 & 0.097 & 0.177 & 0.118 \\
\hline $\mathrm{ST}_{7}$ & 0.057 & 0.030 & 0.084 & 0.073 & 0.217 & 0.342 & $\mathrm{ST}_{7}$ & 0.053 & 0.044 & 0.046 & 0.097 & 0.295 & 0.252 \\
\hline $\mathrm{ST}_{8}$ & 0.047 & 0.031 & 0.105 & 0.073 & 0.217 & 0.228 & $\mathrm{ST}_{8}$ & 0.042 & 0.056 & 0.058 & 0.097 & 0.221 & 0.136 \\
\hline $\mathrm{ST}_{9}$ & 0.045 & 0.018 & 0.094 & 0.073 & 0.124 & 0.124 & $\mathrm{ST}_{9}$ & 0.039 & 0.023 & 0.053 & 0.097 & 0.098 & 0.059 \\
\hline $\mathrm{ST}_{10}$ & 0.045 & 0.034 & 0.084 & 0.073 & 0.217 & 0.304 & $\mathrm{ST}_{10}$ & 0.046 & 0.044 & 0.046 & 0.097 & 0.221 & 0.196 \\
\hline $\mathrm{ST}_{11}$ & 0.049 & 0.057 & 0.060 & 0.073 & 0.217 & 0.391 & $\mathrm{ST}_{11}$ & 0.041 & 0.050 & 0.033 & 0.097 & 0.221 & 0.126 \\
\hline $\mathrm{ST}_{12}$ & 0.041 & 0.018 & 0.168 & 0.110 & 0.109 & 0.083 & $\mathrm{ST}_{12}$ & 0.041 & 0.025 & 0.093 & 0.145 & 0.177 & 0.057 \\
\hline $\mathrm{ST}_{13}$ & 0.051 & 0.025 & 0.084 & 0.073 & 0.217 & 0.304 & $\mathrm{ST}_{13}$ & 0.044 & 0.038 & 0.046 & 0.097 & 0.177 & 0.118 \\
\hline $\mathrm{ST}_{14}$ & 0.049 & 0.025 & 0.084 & 0.073 & 0.217 & 0.249 & $\mathrm{ST}_{14}$ & 0.050 & 0.033 & 0.046 & 0.097 & 0.295 & 0.252 \\
\hline $\mathrm{ST}_{15}$ & 0.044 & 0.021 & 0.126 & 0.073 & 0.079 & 0.098 & $\mathrm{ST}_{15}$ & 0.043 & 0.031 & 0.066 & 0.097 & 0.098 & 0.080 \\
\hline $\mathrm{ST}_{16}$ & 0.047 & 0.026 & 0.105 & 0.073 & 0.124 & 0.171 & $\mathrm{ST}_{16}$ & 0.042 & 0.040 & 0.058 & 0.097 & 0.126 & 0.093 \\
\hline $\mathrm{ST}_{17}$ & 0.050 & 0.036 & 0.084 & 0.073 & 0.217 & 0.304 & $\mathrm{ST}_{17}$ & 0.050 & 0.061 & 0.046 & 0.097 & 0.295 & 0.353 \\
\hline AI & 0.057 & 0.057 & 0.168 & 0.110 & 0.217 & 0.391 & AI & 0.053 & 0.061 & 0.093 & 0.145 & 0.295 & 0.353 \\
\hline
\end{tabular}


TABLE 6: Values for criteria obtained using the DEA model.

\begin{tabular}{lccccccccccccc}
\hline DEA-N & $w_{1}$ & $w_{2}$ & $w_{3}$ & $w_{4}$ & $w_{5}$ & $w_{6}$ & $\mathrm{DEA}-\mathrm{S}$ & $w_{1}$ & $w_{2}$ & $w_{3}$ & $w_{4}$ & $w_{5}$ & $w_{6}$ \\
\hline $\mathrm{ST}_{1}$ & 0.000 & 0.000 & 0.024 & 0.000 & 0.083 & 0.063 & $\mathrm{ST}_{1}$ & 0.000 & 0.000 & 0.000 & 0.015 & 0.088 & 0.059 \\
$\mathrm{ST}_{2}$ & 0.000 & 0.000 & 0.018 & 0.000 & 0.048 & 0.040 & $\mathrm{ST}_{2}$ & 0.000 & 0.000 & 0.000 & 0.000 & 0.036 & 0.043 \\
$\mathrm{ST}_{3}$ & 0.000 & 0.000 & 0.000 & 0.000 & 0.051 & 0.031 & $\mathrm{ST}_{3}$ & 0.000 & 0.000 & 0.000 & 0.000 & 0.060 & 0.038 \\
$\mathrm{ST}_{4}$ & 0.000 & 0.000 & 0.000 & 0.038 & 0.115 & 0.077 & $\mathrm{ST}_{4}$ & 0.000 & 0.000 & 0.000 & 0.023 & 0.136 & 0.091 \\
$\mathrm{ST}_{5}$ & 0.000 & 0.000 & 0.000 & 0.000 & 0.051 & 0.031 & $\mathrm{ST}_{5}$ & 0.000 & 0.000 & 0.000 & 0.000 & 0.052 & 0.033 \\
$\mathrm{ST}_{6}$ & 0.000 & 0.000 & 0.000 & 0.000 & 0.077 & 0.048 & $\mathrm{ST}_{6}$ & 0.000 & 0.000 & 0.006 & 0.000 & 0.099 & 0.067 \\
$\mathrm{ST}_{7}$ & 0.000 & 0.000 & 0.000 & 0.366 & 0.000 & 0.125 & $\mathrm{ST}_{7}$ & 0.000 & 0.000 & 0.061 & 0.000 & 0.000 & 0.143 \\
$\mathrm{ST}_{8}$ & 0.000 & 0.000 & 0.111 & 0.000 & 0.000 & 0.083 & $\mathrm{ST}_{8}$ & 0.000 & 0.000 & 0.007 & 0.000 & 0.115 & 0.077 \\
$\mathrm{ST}_{9}$ & 0.000 & 0.000 & 0.000 & 0.000 & 0.032 & 0.045 & $\mathrm{ST}_{9}$ & 0.000 & 0.000 & 0.000 & 0.000 & 0.028 & 0.033 \\
$\mathrm{ST}_{10}$ & 0.007 & 0.000 & 0.034 & 0.000 & 0.000 & 0.111 & $\mathrm{ST}_{10}$ & 0.000 & 0.000 & 0.000 & 0.000 & 0.093 & 0.111 \\
$\mathrm{ST}_{11}$ & 0.015 & 0.000 & 0.000 & 0.000 & 0.000 & 0.143 & $\mathrm{ST}_{11}$ & 0.001 & 0.000 & 0.000 & 0.000 & 0.105 & 0.071 \\
$\mathrm{ST}_{12}$ & 0.000 & 0.000 & 0.040 & 0.000 & 0.000 & 0.030 & $\mathrm{ST}_{12}$ & 0.000 & 0.000 & 0.014 & 0.000 & 0.000 & 0.032 \\
$\mathrm{ST}_{13}$ & 0.000 & 0.000 & 0.000 & 0.000 & 0.000 & 0.111 & $\mathrm{ST}_{13}$ & 0.000 & 0.000 & 0.000 & 0.000 & 0.056 & 0.067 \\
$\mathrm{ST}_{14}$ & 0.007 & 0.000 & 0.000 & 0.000 & 0.000 & 0.091 & $\mathrm{ST}_{14}$ & 0.000 & 0.000 & 0.000 & 0.183 & 0.000 & 0.143 \\
$\mathrm{ST}_{15}$ & 0.000 & 0.000 & 0.014 & 0.000 & 0.048 & 0.036 & $\mathrm{ST}_{15}$ & 0.000 & 0.000 & 0.004 & 0.000 & 0.068 & 0.045 \\
$\mathrm{ST}_{16}$ & 0.000 & 0.000 & 0.029 & 0.000 & 0.075 & 0.062 & $\mathrm{ST}_{16}$ & 0.000 & 0.000 & 0.005 & 0.000 & 0.078 & 0.053 \\
$\mathrm{ST}_{17}$ & 0.005 & 0.000 & 0.095 & 0.000 & 0.000 & 0.111 & $\mathrm{ST}_{17}$ & 0.000 & 0.000 & 0.000 & 0.500 & 0.000 & 0.200 \\
\hline
\end{tabular}

By applying equations (9) and (10), the values of the criteria according to the DEA-2 model are obtained as follows:

$$
\begin{aligned}
& V_{1 \mathrm{DEA}-2}=0, V_{2 \mathrm{DEA}-2}=0, V_{3 \mathrm{DEA}-2}=0.141, V_{4 \mathrm{DEA}-2}=0, V_{5 \mathrm{DEA}-2}=0.488, V_{6 \mathrm{DEA}-2}=0.371, \\
& V_{3 \mathrm{DEA}-2}=\frac{0.024}{0.170}=0.141, \\
& w_{1 \mathrm{DEA}-2}=0.014, w_{2 \mathrm{DEA}-2}=0.000, w_{3 \mathrm{DEA}-2}=0.144, w_{4 \mathrm{DEA}-2}=0.054, V_{5 \mathrm{DEA}-2}=0.274, V_{6 \mathrm{DEA}-2}=0.515, \\
& w_{1 \mathrm{DEA}-2}=\frac{0+0+0+0+0+0+0+0+0+0.046+0.095+0+0+0.071+0+0+0.024}{17}=0.014 .
\end{aligned}
$$

The previous calculation refers to the N-direction, while the values for the S-direction are obtained in an identical way, which together with the previous calculations and the final values are shown in Figures 3 and 4.

4.4. Determining the Final Criteria Weights. The final values of the criteria are obtained by averaging the weight values of the criteria obtained by individual methods: CRITIC, DEA1 , and DEA-2. Figure 3 presents the individual and final values of the criteria for the N-direction (Figure 3(a)) and the S-direction (Figure 3(b)).

From Figure 3, it can be seen that there is a difference in applying different approaches and that different values are obtained. This is the reason for their integration when obtaining the final values. Using the CRITIC method, the following values are obtained: $w_{1}=0.145, w_{2}=0.170$, $w_{3}=0.220, w_{4}=0.122, w_{5}=0.157$, and $w_{6}=0.187$ for the $\mathrm{N}$-direction and $w_{1}=0.159, \quad w_{2}=0.182, \quad w_{3}=0.204$, $w_{4}=0.120, w_{5}=0.147$, and $w_{6}=0.187$ for the S-direction. In the previous section of the paper, the values obtained using DEA models are explained. The DEA-1 model for the
$\mathrm{N}$-direction implies the values $w_{1}=0.013, w_{2}=0.0003$, $w_{3}=0.139, w_{4}=0.154, w_{5}=0.221$, and $w_{6}=0.472$ and for the S-direction, $w_{1}=0.0003, w_{2}=0.0001, w_{3}=0.031, w_{4}=0.300$, $w_{5}=0.323$, and $w_{6}=0.416$. Applying a different approach, i.e., the DEA-2 model, the values of the criteria for the $\mathrm{N}$-direction are $w_{1}=0.014, w_{2}=0.000, w_{3}=0.144$, $w_{4}=0.054, w_{5}=0.274$, and $w_{6}=0.515$, while for the S-direction, they are $w_{1}=0.0003, w_{2}=0.0001, w_{3}=0.044$, $w_{4}=0.086, w_{5}=0.414$, and $w_{6}=0.456$. Observing the range of weight values of the criteria, including the final values, the largest deviation is for the sixth criterion with a value of 0.328 for the $\mathrm{N}$-direction. There is a slightly smaller deviation for the sixth and fifth criterion for the S-direction. For other criteria, the range of values is smaller.

The final values of the criteria further included in the MARCOS method are $w_{1}=0.057, w_{2}=0.057, w_{3}=0.168$, $w_{4}=0.110, w_{5}=0.217$, and $w_{6}=0.391$ for the N-direction and $w_{1}=0.053, w_{2}=0.061, \quad w_{3}=0.093, \quad w_{4}=0.145$, $w_{5}=0.295$, and $w_{6}=0.353$ for the S-direction. Figure 4 also shows the ranks, i.e., the significance of all criteria according to each individual model and for the final values. The most significant criterion according to DEA-1 and 


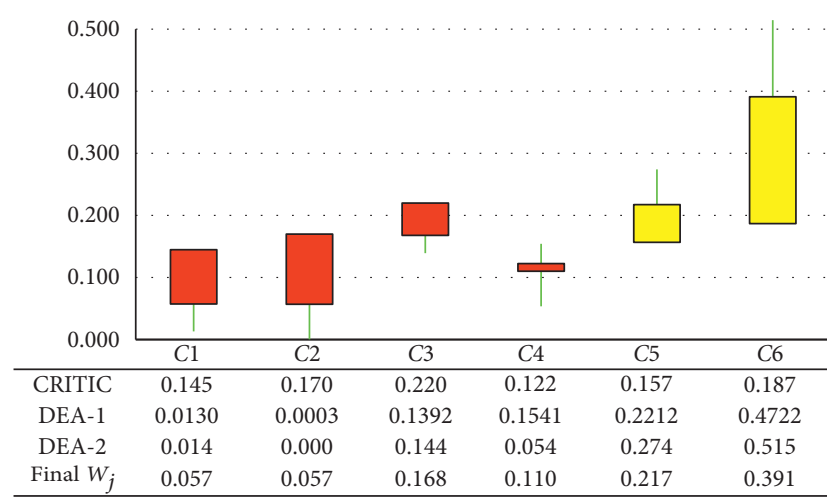

(a)

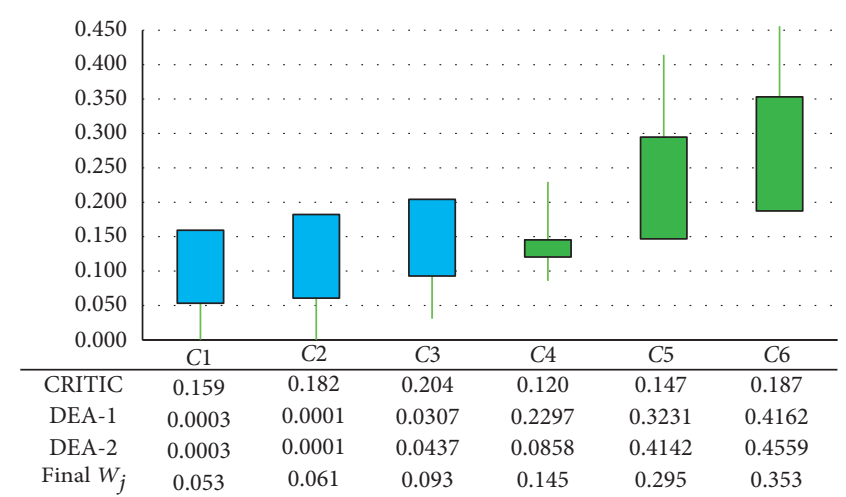

(b)

FIgURE 3: Criteria weights for the N- (a) and S-direction (b) using different approaches.

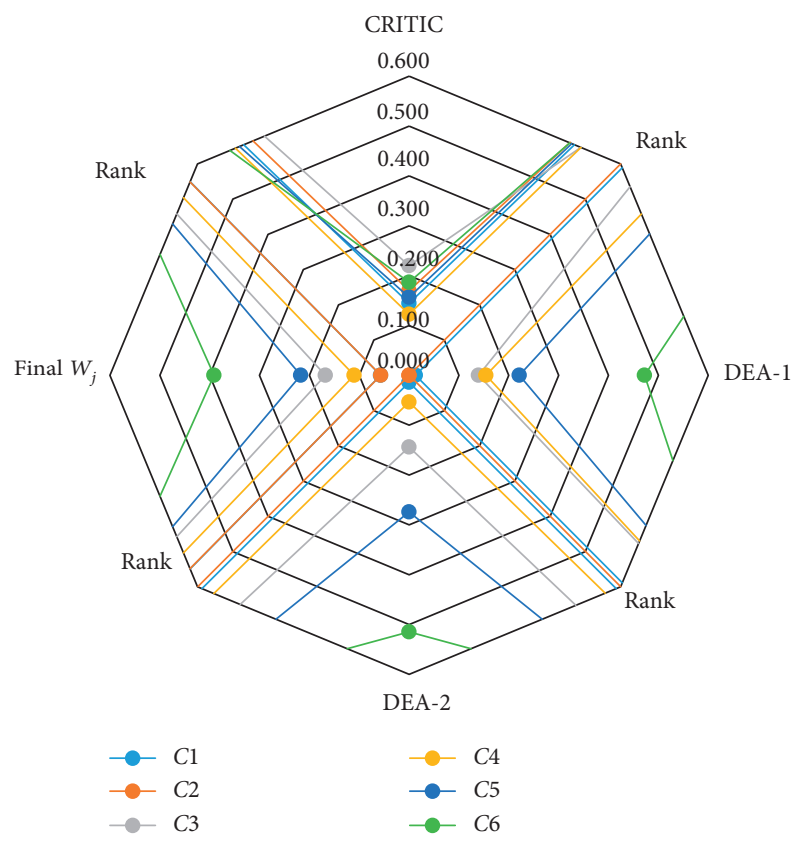

(a)

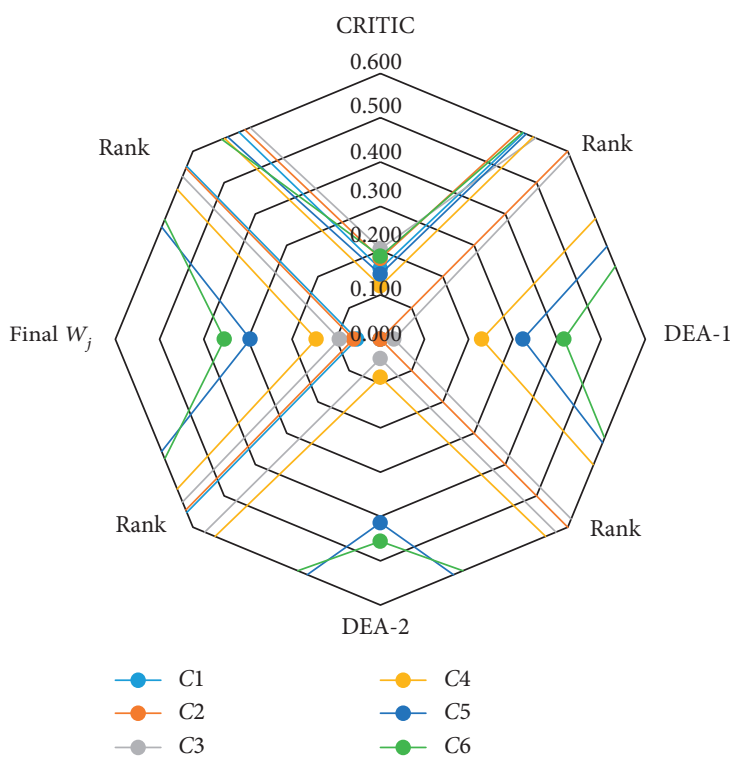

(b)

FIgURE 4: Criteria weights and ranks for the N- (a) and S-direction (b) using different approaches.

DEA-2 models and the final values is the average number of accidents (per $\mathrm{km}$ ), which is understandable, while the same criterion is the second according to the CRIITIC method. The second most significant criterion is the number of access (per $\mathrm{km}$ ) for all models, except for the already mentioned CRITIC, where it is in the fourth position. The third most significant criterion is road width (m) according to the final values and the DEA-2 model, while by applying DEA-1, it is in the fourth place, i.e., in the first place by applying the CRITIC method. The fourth criterion, the number of lanes, is positioned in the fourth place, while the last two places occupy the first and second criterion, respectively. The listed ranks and significance refer to the left side of the figure which implies the N-direction. When it comes to the significance of the criteria for the S-direction, it can be concluded that the ranks are more correlated than for the $\mathrm{N}$-direction. The difference in the final values in terms of ranks is only for the third and fourth criterion, which change positions with each other.

4.5. Evaluation of Alternatives Using the MARCOS Method. The following section of the paper presents the evaluation of alternatives using the MARCOS method. For each step of the method, an example of the calculation is given in order to facilitate the monitoring of the obtained results. Table 7 shows an extended initial decision matrix obtained when Table 1 is expanded with an ideal (AI) and an anti-ideal (AAI) solution depending on the type of criteria. It is important to emphasize that the third and fourth criterion are of the benefit type (orientation max), while the others are of the cost type (orientation min).

Applying equation (14), the normalized values for cost criteria are obtained, e.g., $n_{N 11}=58 / 71=0.817, n_{S 11}=$ 
TABLE 7: An extended initial decision matrix.

\begin{tabular}{|c|c|c|c|c|c|c|c|c|c|c|c|c|c|}
\hline $\mathrm{N}$ & $C_{1}$ & $C_{2}$ & $C_{3}$ & $C_{4}$ & $C_{5}$ & $C_{6}$ & S & $C_{1}$ & $C_{2}$ & $C_{3}$ & $C_{4}$ & $C_{5}$ & $C_{6}$ \\
\hline AAI & 81 & 10055 & 4.3 & 1 & 15 & 33 & AAI & 78 & 11669 & 4.3 & 1 & 12 & 31 \\
\hline $\mathrm{ST}_{1}$ & 71 & 4611 & 6.2 & 2 & 8 & 16 & $\mathrm{ST}_{1}$ & 69 & 5082 & 6.2 & 2 & 7 & 17 \\
\hline $\mathrm{ST}_{2}$ & 76 & 8908 & 6.5 & 2 & 8 & 25 & $\mathrm{ST}_{2}$ & 73 & 9359 & 6.7 & 2 & 7 & 23 \\
\hline $\mathrm{ST}_{3}$ & 79 & 9938 & 6.1 & 1 & 9 & 32 & $\mathrm{ST}_{3}$ & 75 & 10133 & 6.2 & 1 & 11 & 26 \\
\hline $\mathrm{ST}_{4}$ & 77 & 8888 & 6.0 & 2 & 8 & 13 & $\mathrm{ST}_{4}$ & 74 & 9009 & 6.4 & 2 & 7 & 11 \\
\hline $\mathrm{ST}_{5}$ & 72 & 9285 & 7.5 & 2 & 15 & 32 & $\mathrm{ST}_{5}$ & 70 & 9133 & 7.5 & 2 & 12 & 30 \\
\hline $\mathrm{ST}_{6}$ & 75 & 7409 & 7.0 & 2 & 11 & 21 & $\mathrm{ST}_{6}$ & 74 & 6171 & 7 & 2 & 5 & 15 \\
\hline $\mathrm{ST}_{7}$ & 58 & 6040 & 6.0 & 2 & 4 & 8 & $\mathrm{ST}_{7}$ & 57 & 5929 & 6 & 2 & 3 & 7 \\
\hline $\mathrm{ST}_{8}$ & 71 & 5888 & 7.5 & 2 & 4 & 12 & $\mathrm{ST}_{8}$ & 73 & 4696 & 7.5 & 2 & 4 & 13 \\
\hline $\mathrm{ST}_{9}$ & 73 & 10055 & 6.7 & 2 & 7 & 22 & $\mathrm{ST}_{9}$ & 78 & 11669 & 6.8 & 2 & 9 & 30 \\
\hline $\mathrm{ST}_{10}$ & 74 & 5444 & 6.0 & 2 & 4 & 9 & $\mathrm{ST}_{10}$ & 66 & 5962 & 6 & 2 & 4 & 9 \\
\hline $\mathrm{ST}_{11}$ & 67 & 3227 & 4.3 & 2 & 4 & 7 & $\mathrm{ST}_{11}$ & 74 & 5257 & 4.3 & 2 & 4 & 14 \\
\hline $\mathrm{ST}_{12}$ & 81 & 10016 & 12.0 & 3 & 8 & 33 & $\mathrm{ST}_{12}$ & 74 & 10636 & 12 & 3 & 5 & 31 \\
\hline $\mathrm{ST}_{13}$ & 65 & 7434 & 6.0 & 2 & 4 & 9 & $\mathrm{ST}_{13}$ & 69 & 6980 & 6 & 2 & 5 & 15 \\
\hline $\mathrm{ST}_{14}$ & 67 & 7267 & 6.0 & 2 & 4 & 11 & $\mathrm{ST}_{14}$ & 61 & 7879 & 6 & 2 & 3 & 7 \\
\hline $\mathrm{ST}_{15}$ & 75 & 8693 & 9.0 & 2 & 11 & 28 & $\mathrm{ST}_{15}$ & 71 & 8500 & 8.5 & 2 & 9 & 22 \\
\hline $\mathrm{ST}_{16}$ & 70 & 7047 & 7.5 & 2 & 7 & 16 & $\mathrm{ST}_{16}$ & 72 & 6654 & 7.5 & 2 & 7 & 19 \\
\hline $\mathrm{ST}_{17}$ & 66 & 5029 & 6.0 & 2 & 4 & 9 & $\mathrm{ST}_{17}$ & 61 & 4330 & 6 & 2 & 3 & 5 \\
\hline AI & 58 & 3227 & 12.0 & 3 & 4 & 7 & AI & 57 & 4330 & 12.0 & 3 & 3 & 5 \\
\hline
\end{tabular}

TABle 8: Normalized matrix.

\begin{tabular}{|c|c|c|c|c|c|c|c|c|c|c|c|c|c|}
\hline $\mathrm{N}$ & $C_{1}$ & $C_{2}$ & $C_{3}$ & $C_{4}$ & $C_{5}$ & $C_{6}$ & $S$ & $C_{1}$ & $C_{2}$ & $C_{3}$ & $C_{4}$ & $C_{5}$ & $C_{6}$ \\
\hline AAI & 0.716 & 0.321 & 0.358 & 0.333 & 0.267 & 0.212 & AAI & 0.731 & 0.371 & 0.358 & 0.333 & 0.250 & 0.161 \\
\hline $\mathrm{ST}_{1}$ & 0.817 & 0.700 & 0.517 & 0.667 & 0.500 & 0.438 & $\mathrm{ST}_{1}$ & 0.826 & 0.852 & 0.517 & 0.667 & 0.429 & 0.294 \\
\hline $\mathrm{ST}_{2}$ & 0.763 & 0.362 & 0.542 & 0.667 & 0.500 & 0.280 & $\mathrm{ST}_{2}$ & 0.781 & 0.463 & 0.558 & 0.667 & 0.429 & 0.217 \\
\hline $\mathrm{ST}_{3}$ & 0.734 & 0.325 & 0.508 & 0.333 & 0.444 & 0.219 & $\mathrm{ST}_{3}$ & 0.760 & 0.427 & 0.517 & 0.333 & 0.273 & 0.192 \\
\hline $\mathrm{ST}_{4}$ & 0.753 & 0.363 & 0.500 & 0.667 & 0.500 & 0.538 & $\mathrm{ST}_{4}$ & 0.770 & 0.481 & 0.533 & 0.667 & 0.429 & 0.455 \\
\hline $\mathrm{ST}_{5}$ & 0.806 & 0.348 & 0.625 & 0.667 & 0.267 & 0.219 & $\mathrm{ST}_{5}$ & 0.814 & 0.474 & 0.625 & 0.667 & 0.250 & 0.167 \\
\hline $\mathrm{ST}_{6}$ & 0.773 & 0.436 & 0.583 & 0.667 & 0.364 & 0.333 & $\mathrm{ST}_{6}$ & 0.770 & 0.702 & 0.583 & 0.667 & 0.600 & 0.333 \\
\hline $\mathrm{ST}_{7}$ & 1.000 & 0.534 & 0.500 & 0.667 & 1.000 & 0.875 & $\mathrm{ST}_{7}$ & 1.000 & 0.730 & 0.500 & 0.667 & 1.000 & 0.714 \\
\hline $\mathrm{ST}_{8}$ & 0.817 & 0.548 & 0.625 & 0.667 & 1.000 & 0.583 & $\mathrm{ST}_{8}$ & 0.781 & 0.922 & 0.625 & 0.667 & 0.750 & 0.385 \\
\hline $\mathrm{ST}_{9}$ & 0.795 & 0.321 & 0.558 & 0.667 & 0.571 & 0.318 & $\mathrm{ST}_{9}$ & 0.731 & 0.371 & 0.567 & 0.667 & 0.333 & 0.167 \\
\hline $\mathrm{ST}_{10}$ & 0.784 & 0.593 & 0.500 & 0.667 & 1.000 & 0.778 & $\mathrm{ST}_{10}$ & 0.864 & 0.726 & 0.500 & 0.667 & 0.750 & 0.556 \\
\hline $\mathrm{ST}_{11}$ & 0.866 & 1.000 & 0.358 & 0.667 & 1.000 & 1.000 & $\mathrm{ST}_{11}$ & 0.770 & 0.824 & 0.358 & 0.667 & 0.750 & 0.357 \\
\hline $\mathrm{ST}_{12}$ & 0.716 & 0.322 & 1.000 & 1.000 & 0.500 & 0.212 & $\mathrm{ST}_{12}$ & 0.770 & 0.407 & 1.000 & 1.000 & 0.600 & 0.161 \\
\hline $\mathrm{ST}_{13}$ & 0.892 & 0.434 & 0.500 & 0.667 & 1.000 & 0.778 & $\mathrm{ST}_{13}$ & 0.826 & 0.620 & 0.500 & 0.667 & 0.600 & 0.333 \\
\hline $\mathrm{ST}_{14}$ & 0.866 & 0.444 & 0.500 & 0.667 & 1.000 & 0.636 & $\mathrm{ST}_{14}$ & 0.934 & 0.550 & 0.500 & 0.667 & 1.000 & 0.714 \\
\hline $\mathrm{ST}_{15}$ & 0.773 & 0.371 & 0.750 & 0.667 & 0.364 & 0.250 & $\mathrm{ST}_{15}$ & 0.803 & 0.509 & 0.708 & 0.667 & 0.333 & 0.227 \\
\hline $\mathrm{ST}_{16}$ & 0.829 & 0.458 & 0.625 & 0.667 & 0.571 & 0.438 & $\mathrm{ST}_{16}$ & 0.792 & 0.651 & 0.625 & 0.667 & 0.429 & 0.263 \\
\hline $\mathrm{ST}_{17}$ & 0.879 & 0.642 & 0.500 & 0.667 & 1.000 & 0.778 & $\mathrm{ST}_{17}$ & 0.934 & 1.000 & 0.500 & 0.667 & 1.000 & 1.000 \\
\hline $\mathrm{AI}$ & 1.000 & 1.000 & 1.000 & 1.000 & 1.000 & 1.000 & $\mathrm{AI}$ & 1.000 & 1.000 & 1.000 & 1.000 & 1.000 & 1.000 \\
\hline
\end{tabular}

$57 / 69=0.826$, and for benefit criteria using equation (15), $n_{N 13}=6.2 / 12=0.517, n_{S 14}=2 / 3=0.667$, and a complete normalized matrix, shown in Table 8 , is obtained.

The next step is weighting the normalized matrix using equation (16) by multiplying all the values of the normalized matrix with the values of the criteria. The weighted normalized matrix is shown in Table 5.

Applying equations (17)-(22), the final results of Table 9 are obtained using the MARCOS method. The results are obtained as follows.

By applying equation (19), all the values (by rows) for alternatives are summarized as follows:
$S_{\mathrm{NAAI}}=0.041+0.018+0.060+0.037+0.058+0.083=0.297$,

$S_{\text {SAAI }}=0.039+0.023+0.033+0.048+0.074+0.057=0.274$.

Similarly, the values for the remaining alternatives are obtained for both directions.

By applying equation (17), the utility degrees in relation to the anti-ideal solution are calculated. The example of the calculation is

$$
K_{N 1}^{-}=\frac{0.526}{0.297}=1.773, K_{S 1}^{-}=\frac{0.471}{0.274}=1.719,
$$


TABLE 9: Alternative ranking obtained using the MARCOS method.

\begin{tabular}{|c|c|c|c|c|c|c|c|c|c|c|c|c|c|c|c|}
\hline $\mathrm{N}$ & $S_{i}$ & $K_{i}^{-}$ & $K_{i}^{+}$ & $f K$ & $f K^{+}$ & $K_{i}$ & Rank & S & $S_{i}$ & $K_{i}^{-}$ & $K_{i}^{+}$ & $f K^{-}$ & $f K^{+}$ & $K_{i}$ & Rank \\
\hline AAI & 0.297 & 1.000 & & & & & & AAI & 0.274 & 1.000 & & & & & \\
\hline $\mathrm{ST}_{1}$ & 0.526 & 1.773 & 0.526 & 0.771 & 0.229 & 0.493 & 11 & $\mathrm{ST}_{1}$ & 0.471 & 1.719 & 0.471 & 0.215 & 0.785 & 0.445 & 11 \\
\hline $\mathrm{ST}_{2}$ & 0.446 & 1.504 & 0.446 & 0.771 & 0.229 & 0.418 & 14 & $\mathrm{ST}_{2}$ & 0.421 & 1.539 & 0.421 & 0.215 & 0.785 & 0.398 & 13 \\
\hline $\mathrm{ST}_{3}$ & 0.364 & 1.228 & 0.364 & 0.771 & 0.229 & 0.341 & 17 & $\mathrm{ST}_{3}$ & 0.311 & 1.136 & 0.311 & 0.215 & 0.785 & 0.294 & 17 \\
\hline $\mathrm{ST}_{4}$ & 0.540 & 1.820 & 0.540 & 0.771 & 0.229 & 0.506 & 9 & $\mathrm{ST}_{4}$ & 0.503 & 1.839 & 0.503 & 0.215 & 0.785 & 0.475 & 10 \\
\hline $\mathrm{ST}_{5}$ & 0.387 & 1.305 & 0.387 & 0.771 & 0.229 & 0.363 & 16 & $\mathrm{ST}_{5}$ & 0.360 & 1.313 & 0.360 & 0.215 & 0.785 & 0.340 & 16 \\
\hline $\mathrm{ST}_{6}$ & 0.449 & 1.514 & 0.449 & 0.771 & 0.229 & 0.421 & 13 & $\mathrm{ST}_{6}$ & 0.529 & 1.933 & 0.529 & 0.215 & 0.785 & 0.500 & 8 \\
\hline $\mathrm{ST}_{7}$ & 0.804 & 2.710 & 0.804 & 0.771 & 0.229 & 0.753 & 2 & $\mathrm{ST}_{7}$ & 0.788 & 2.877 & 0.788 & 0.215 & 0.785 & 0.744 & 2 \\
\hline $\mathrm{ST}_{8}$ & 0.701 & 2.363 & 0.701 & 0.771 & 0.229 & 0.657 & 6 & $\mathrm{ST}_{8}$ & 0.609 & 2.225 & 0.609 & 0.215 & 0.785 & 0.575 & 5 \\
\hline $\mathrm{ST}_{9}$ & 0.479 & 1.615 & 0.479 & 0.771 & 0.229 & 0.449 & 12 & $\mathrm{ST}_{9}$ & 0.368 & 1.344 & 0.368 & 0.215 & 0.785 & 0.348 & 15 \\
\hline $\mathrm{ST}_{10}$ & 0.757 & 2.551 & 0.757 & 0.771 & 0.229 & 0.709 & 4 & $\mathrm{ST}_{10}$ & 0.651 & 2.376 & 0.651 & 0.215 & 0.785 & 0.614 & 4 \\
\hline $\mathrm{ST}_{11}$ & 0.848 & 2.857 & 0.848 & 0.771 & 0.229 & 0.794 & 1 & $\mathrm{ST}_{11}$ & 0.568 & 2.076 & 0.568 & 0.215 & 0.785 & 0.537 & 6 \\
\hline $\mathrm{ST}_{12}$ & 0.528 & 1.781 & 0.528 & 0.771 & 0.229 & 0.495 & 10 & $\mathrm{ST}_{12}$ & 0.538 & 1.964 & 0.538 & 0.215 & 0.785 & 0.508 & 7 \\
\hline $\mathrm{ST}_{13}$ & 0.754 & 2.541 & 0.754 & 0.771 & 0.229 & 0.706 & 5 & $\mathrm{ST}_{13}$ & 0.520 & 1.897 & 0.520 & 0.215 & 0.785 & 0.491 & 9 \\
\hline $\mathrm{ST}_{14}$ & 0.698 & 2.352 & 0.698 & 0.771 & 0.229 & 0.654 & 7 & $\mathrm{ST}_{14}$ & 0.773 & 2.824 & 0.773 & 0.215 & 0.785 & 0.730 & 3 \\
\hline $\mathrm{ST}_{15}$ & 0.441 & 1.486 & 0.441 & 0.771 & 0.229 & 0.413 & 15 & $\mathrm{ST}_{15}$ & 0.415 & 1.515 & 0.415 & 0.215 & 0.785 & 0.392 & 14 \\
\hline $\mathrm{ST}_{16}$ & 0.547 & 1.842 & 0.547 & 0.771 & 0.229 & 0.512 & 8 & $\mathrm{ST}_{16}$ & 0.456 & 1.665 & 0.456 & 0.215 & 0.785 & 0.430 & 12 \\
\hline $\mathrm{ST}_{17}$ & 0.765 & 2.579 & 0.765 & 0.771 & 0.229 & 0.717 & 3 & $\mathrm{ST}_{17}$ & 0.902 & 3.293 & 0.902 & 0.215 & 0.785 & 0.852 & 1 \\
\hline AI & 1.000 & & & & & & & AI & 1.000 & & & & & & \\
\hline
\end{tabular}

while using equation (18), the utility degrees in relation to the ideal solution are obtained, e.g.,

$$
K_{N+}^{-}=\frac{0.526}{1.000}=0.526, K_{S 1}^{-}=\frac{0.471}{0.297}=0.471 .
$$

The utility function in terms of the anti-ideal solution is obtained using equation (21) as follows:

$$
\begin{aligned}
& f\left(K_{N 1}^{-}\right)=\frac{0.526}{0.526+1.773}=0.229 \\
& f\left(K_{S 1}^{-}\right)=\frac{0.471}{0.471+1.719}=0.215
\end{aligned}
$$

while the utility function in terms of the ideal solution is obtained using equation (22) as follows:

$$
\begin{aligned}
& f\left(K_{N 1}^{+}\right)=\frac{1.773}{0.526+1.773}=0.771 \\
& f\left(K_{S 1}^{+}\right)=\frac{1.719}{0.471+1.719}=0.785
\end{aligned}
$$

Finally, the utility function of alternative A1 is obtained by applying equation (20):

$$
\begin{aligned}
& f\left(K_{N 1}\right)=\frac{0.526+1.773}{1+1-0.771 / 0.771+1-0.229 / 0.229}=0.493, \\
& f\left(K_{S 1}\right)=\frac{0.471+1.719}{1+1-0.785 / 0.785+1-0.215 / 0.215}=0.445 .
\end{aligned}
$$

After applying the whole methodology, the results for both directions are summarized in Table 9. When it comes to the rank, i.e., determination of the traffic safety level in 17 streets of the city of Bloemfontein, it can be noticed that alternative A11, i.e., Van Schalkwyk Street, is the safest with a value of 0.794 for the $\mathrm{N}$-direction. Volkspele Drive is the second in terms of safety, with Eric Rosendorf Street and Gardenia Avenue in the third and fourth place, respectively. Another alternative A13, i.e., Edeling Street, can be put into a group of safe streets comparing all alternatives. The group of most risky streets includes Wynand Mouton Drive, Paul Kruger Drive North, Benade Drive (N), Totius Street, and Paul Kruger Drive South with a range of values from 0.341 to 0.421 .

As already mentioned in the previous section of the paper, data have been collected for both directions, and the evaluation is performed accordingly, so it is evident that there are differences in terms of safety of individual streets. When it comes to the S-direction, the group of the five safest streets includes the following, respectively: Eric Rosendorf Street, Volkspele Drive, Stals Road, Gardenia Avenue, and Pellissier Drive. The group of least safe streets for the S-direction includes Wynand Mouton Drive, Paul Kruger Drive North, Paul Kruger Drive (E), and Benade Drive (N).

Three streets that belong to the group of safe regardless of the direction are Eric Rosendorf Street, third and first positions, Volkspele Drive, second place for both directions, and Gardenia Avenue which is in the fourth place. In terms of the most risky streets for both directions, Wynand Mouton Drive is in the last place, Paul Kruger Drive North in the 16th place, Benade Drive (N) in the 15th and 14th place, respectively, and Totius Street in the 14th and 13th place, respectively.

\section{Sensitivity Analysis}

Verification of previously obtained results was performed through a multiphase sensitivity analysis. Validity tests refer to the (a) formation of reverse rank matrices in which the 

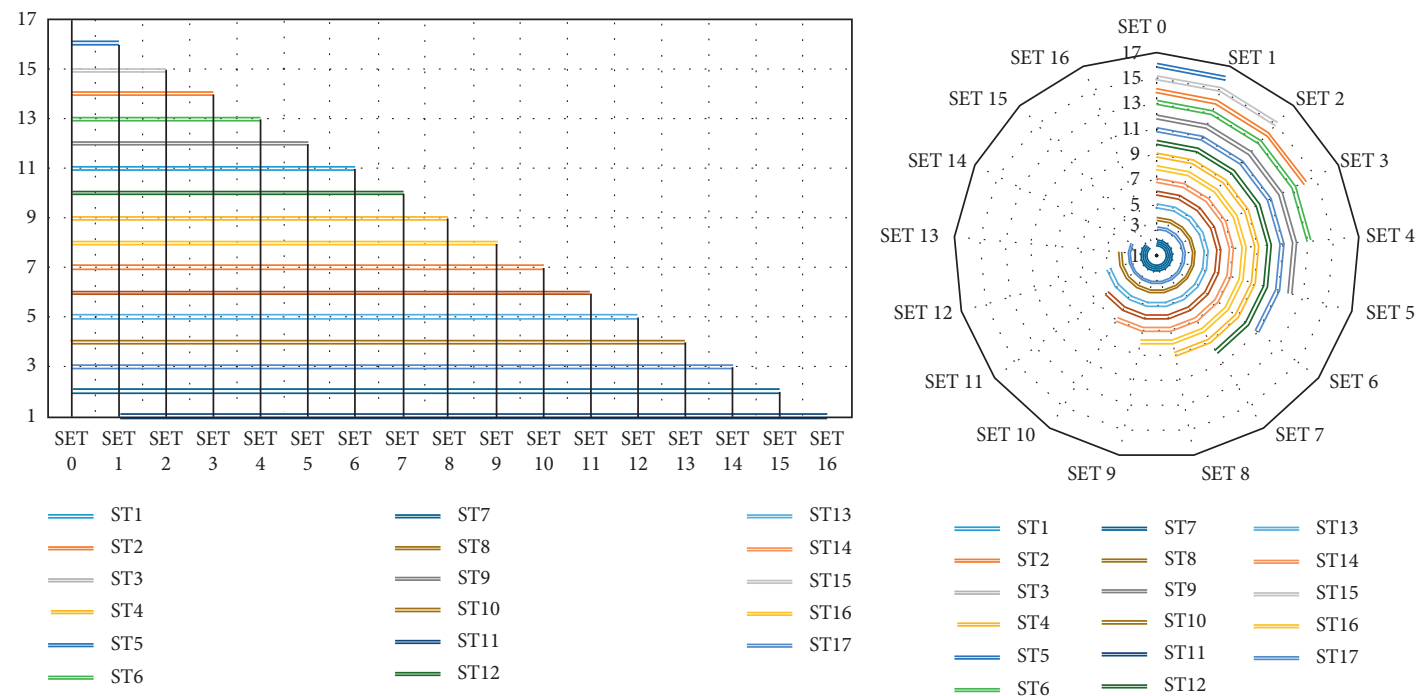

FIGURE 5: Results of reverse rank for both directions.

worst alternative is eliminated from further calculation, (b) change of criterion weight in a dynamic environment, (c) evaluation of alternatives based on individually obtained values of criteria weights using CRITIC, DEA-1, and DEA-2 methods; in addition, a scenario is created in which all criteria have equal significance, $(d)$ comparative analysis of the obtained results with five other MCDM methods, (e) calculation of SCC for all ranks obtained by applying different approaches, and (f) calculation of standard deviation of ranks obtained by applying different approaches.

5.1. Reverse Rank Matrix. In this part of the sensitivity analysis, the worst alternative is eliminated through 16 scenarios. In each of the scenarios, the last-ranked alternative is eliminated, and a full calculation is performed again, until one alternative remains, as is the case in scenario 16.

Figure 5 presents the results of the ranks of alternatives through previously formed scenarios for both directions. As can be seen, there is no change in ranks in any case, which means that the model is stable, and the results are valid in such conditions.

5.2. Changing Criteria Weights. In this phase of the validation test, the impact of changing the three most important criteria C6, C5, and C3 for the N-direction and C6, C5, and $\mathrm{C} 4$ for the S-direction on ranking results was analyzed. Applying equation (33), a total of 18 scenarios were formed.

$$
W_{n \beta}=\left(1-W_{n \alpha}\right) \frac{W_{\beta}}{\left(1-W_{n}\right)} .
$$

The sixth criterion was changed in scenarios $S 1-S 6$, criterion $C 5$ was changed in scenarios $S 7-S 12$, and criterion $C 3$ was changed in scenarios $S 13-S 18$ for the $\mathrm{N}$-direction. In equation (33), $\widetilde{W}_{n \beta}$ represents the new value of criteria $C 1-C 5$ for scenarios $S 1-S 6$ and then $C 1-C 4$ and $C 5$ for scenarios $57-S 12$, i.e., C1-C2, C4, and C5-C6 for scenarios $S 13-S 18 . \widetilde{W}_{n \alpha}$ represents the corrected value of criteria $C 6$, $C 5$, and $C 3$, respectively, by groups of scenarios, $\widetilde{W}_{\beta}$ represents the original value of the criterion considered, and $\widetilde{W}_{n}$ represents the original value of the criterion whose value is reduced, in this case, $C 6, C 5$, and $C 3$.

For the S-direction, the difference is that, in scenarios S13-S18, the value of criterion C4 was changed instead of C3.

In all scenarios, the value of criteria was reduced by $15 \%$, while the values of the remaining criteria were proportionally corrected by applying equation (33). After forming 18 new vectors of the weight coefficients of the criteria (Table 10), new results were obtained, as presented in Figure 6.

Figure 6(a) presents the ranks of alternatives for the $\mathrm{N}$-direction due to the formation of 18 scenarios with new criteria weights. As can be seen, the rank changes due to the simulation of different values of the criteria, which means that the results are sensitive to the significance of the criteria. The biggest changes compared to the initial rank (SET 0) occur in the sixth set when alternative ST11 falls from the first to the third place. The consequence of such a change is in the value of the sixth criterion, which is only 0.039 . If we take into account that, in real conditions, the sixth criterion should not have such a low value, it remains the best alternative option. In the sixth scenario, dominant criteria are the fifth and the third, which consequently influence the sixth-ranked alternative to become the first compared to the initial ranking. In other scenarios, there is also a change in ranks, but they are negligible compared to the above scenario.

When it comes to changes of ranks for the S-direction, Figure 6(b), smaller changes can be noticed, i.e., greater stability of the initial rank. The best three alternatives ST17, ST7, and ST14 do not change the ranks of the alternatives at all regardless of the criteria values. In addition, there are fewer changes through the other scenarios, with the 
TABLE 10: New criteria weights through 18 scenarios.

\begin{tabular}{lccccccccccccc}
\hline $\mathrm{N}$ & $w_{1}$ & $w_{2}$ & $w_{3}$ & $w_{4}$ & $w_{5}$ & $w_{6}$ & $\mathrm{~S}$ & $w_{1}$ & $w_{2}$ & $w_{3}$ & $w_{4}$ & $w_{5}$ & $w_{6}$ \\
\hline$S_{1}$ & 0.063 & 0.062 & 0.184 & 0.121 & 0.238 & 0.332 & $S_{1}$ & 0.058 & 0.066 & 0.100 & 0.157 & 0.319 & 0.300 \\
$S_{2}$ & 0.068 & 0.068 & 0.200 & 0.131 & 0.259 & 0.274 & $S_{2}$ & 0.062 & 0.071 & 0.108 & 0.169 & 0.343 & 0.247 \\
$S_{3}$ & 0.074 & 0.073 & 0.216 & 0.142 & 0.280 & 0.215 & $S_{3}$ & 0.066 & 0.076 & 0.116 & 0.181 & 0.367 & 0.194 \\
$S_{4}$ & 0.079 & 0.079 & 0.232 & 0.152 & 0.301 & 0.156 & $S_{4}$ & 0.071 & 0.081 & 0.123 & 0.193 & 0.391 & 0.141 \\
$S_{5}$ & 0.085 & 0.084 & 0.248 & 0.163 & 0.322 & 0.098 & $S_{5}$ & 0.075 & 0.086 & 0.131 & 0.205 & 0.415 & 0.088 \\
$S_{6}$ & 0.090 & 0.090 & 0.265 & 0.174 & 0.343 & 0.039 & $S_{6}$ & 0.079 & 0.091 & 0.138 & 0.217 & 0.439 & 0.035 \\
$S_{7}$ & 0.060 & 0.059 & 0.175 & 0.115 & 0.185 & 0.407 & $S_{7}$ & 0.057 & 0.065 & 0.099 & 0.154 & 0.250 & 0.375 \\
$S_{8}$ & 0.062 & 0.061 & 0.182 & 0.119 & 0.152 & 0.424 & $S_{8}$ & 0.060 & 0.068 & 0.104 & 0.163 & 0.206 & 0.397 \\
$S_{9}$ & 0.064 & 0.064 & 0.189 & 0.124 & 0.120 & 0.440 & $S_{9}$ & 0.063 & 0.072 & 0.110 & 0.173 & 0.162 & 0.420 \\
$S_{10}$ & 0.067 & 0.066 & 0.196 & 0.128 & 0.087 & 0.456 & $S_{10}$ & 0.067 & 0.076 & 0.116 & 0.182 & 0.118 & 0.442 \\
$S_{11}$ & 0.069 & 0.069 & 0.203 & 0.133 & 0.054 & 0.473 & $S_{11}$ & 0.070 & 0.080 & 0.122 & 0.191 & 0.074 & 0.464 \\
$S_{12}$ & 0.071 & 0.071 & 0.210 & 0.137 & 0.022 & 0.489 & $S_{12}$ & 0.073 & 0.084 & 0.128 & 0.200 & 0.029 & 0.486 \\
$S_{13}$ & 0.059 & 0.058 & 0.143 & 0.113 & 0.224 & 0.403 & $S_{13}$ & 0.055 & 0.062 & 0.095 & 0.123 & 0.302 & 0.362 \\
$S_{14}$ & 0.061 & 0.060 & 0.117 & 0.117 & 0.230 & 0.415 & $S_{14}$ & 0.056 & 0.064 & 0.098 & 0.102 & 0.310 & 0.371 \\
$S_{15}$ & 0.062 & 0.062 & 0.092 & 0.120 & 0.237 & 0.427 & $S_{15}$ & 0.057 & 0.065 & 0.100 & 0.080 & 0.317 & 0.380 \\
$S_{16}$ & 0.064 & 0.064 & 0.067 & 0.123 & 0.244 & 0.438 & $S_{16}$ & 0.059 & 0.067 & 0.102 & 0.058 & 0.325 & 0.389 \\
$S_{17}$ & 0.066 & 0.065 & 0.042 & 0.127 & 0.250 & 0.450 & $S_{17}$ & 0.060 & 0.069 & 0.105 & 0.036 & 0.332 & 0.398 \\
$S_{18}$ & 0.068 & 0.067 & 0.017 & 0.130 & 0.257 & 0.462 & $S_{18}$ & 0.061 & 0.070 & 0.107 & 0.015 & 0.340 & 0.407 \\
\hline
\end{tabular}
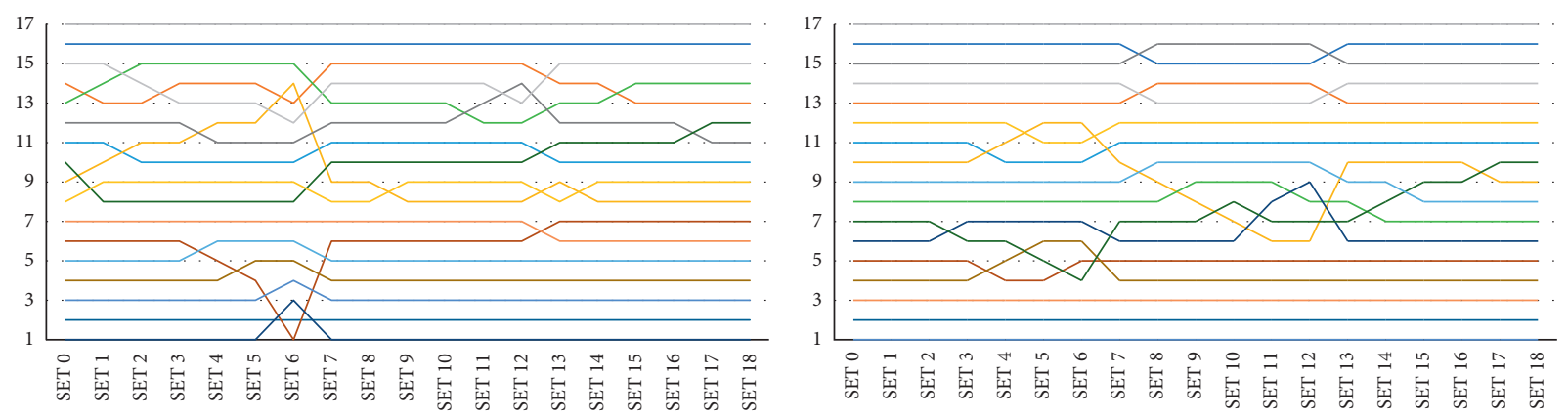

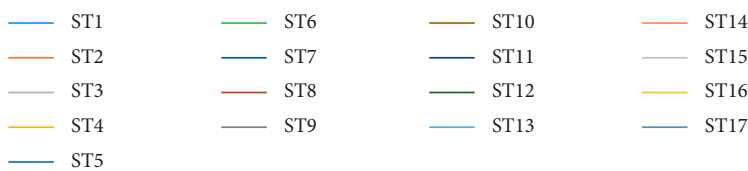

(a)

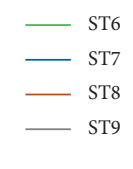

(b)

FIGURE 6: Results of using different criteria weights for the (a) N-direction and (b) S-direction.

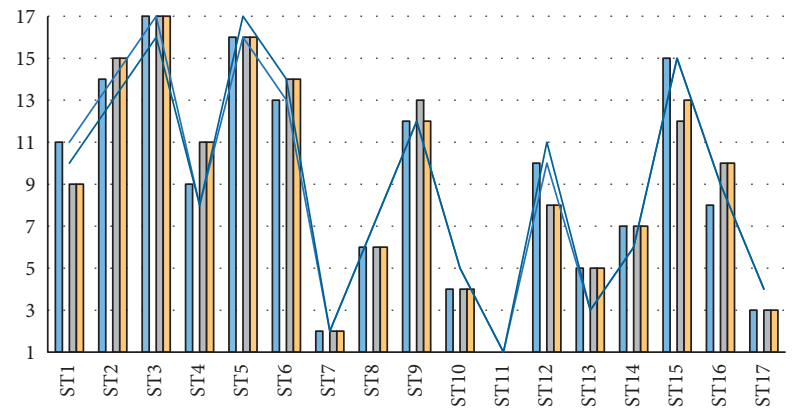

MARCOS
CM
Equal weights

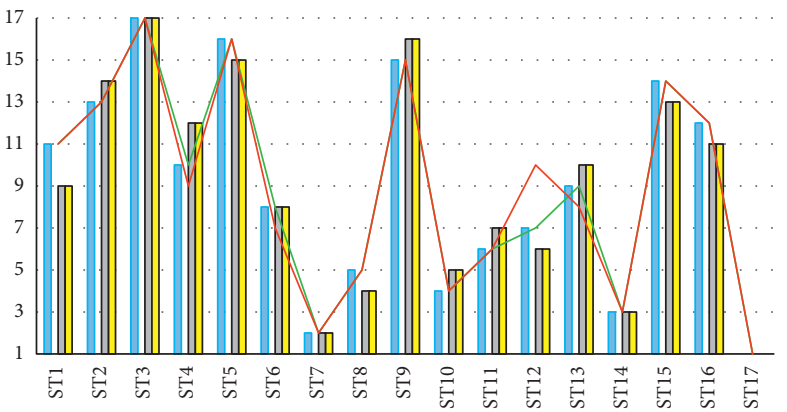

$=$ MARCOS
$\sqsubset$ CM
$\sqsubset$ Equal weights

— DEA-1-MARCOS

- DEA-2-MARCOS

(a)

(b)

FIGURE 7: Results of sensitivity analysis with various approaches for determining criteria weights. 
exception of SET11 and SET12 in which changes occur by four positions, which refer to ST4 which moves from the tenth position to the sixth. Taking into account the large changes in the significance of the criteria, it can be concluded that the changes in the ranks are not huge, which will be proven later through the calculation of the correlation of ranks.

In addition to creating dynamic matrices in which the values of the criteria weights change, this part of the sensitivity analysis shows a comparison of the ranks of the proposed model with CRITIC-MARCOS (CM), DEA-1MARCOS, and DEA-2-MARCOS models and an approach with equal criteria weights, which is shown in Figure 7.

Figure 7(a) presents the ranks for the $\mathrm{N}$-direction under different approaches to determine the weight values of the criteria. The first two best alternatives retain their positions regardless of the approach applied, while ST17 falls from the third position to the fourth using the DEA-1-MARCOS and DEA-2-MARCOS models, respectively. The biggest changes are related to the change of rank by two places compared to the initial results. When it comes to the S-direction, Figure 7(b), the results are similar, with three best-positioned alternatives retaining their places for all applied approaches. In addition, it can be concluded that the model is sensitive to the application of different approaches, but the results are highly correlated.

5.3. Comparison with Other MCDM Methods. In this section of the paper, a comparative analysis is performed with five other MCDM methods: ARAS-additive ratio assessment [29], MABAC-multiattributive border approximation area comparison [30, 31], SAW-simple additive weighting method [32], WASPAS - weighted aggregated sum product assessment [33, 34], and EDAS-evaluation based on distance from average solution [35]. Figure 8 shows the results of a comparative analysis for the $\mathrm{N}$-direction, while Figure 9 shows a comparative analysis for the S-direction.

By applying the MABAC method, alternative ST11 takes the second position, while by applying all other methods, it represents the best solution. Essentially, the two best alternatives, ST11 and ST7, change their ranks with each other when calculating with the MABAC method. Alternative ST17 is in the third position using all MCDM methods. When it comes to the fourth and fifth position, the situation is the same as for the previously mentioned changes where ST10 and ST13 change their ranks with each other in the MABAC method. The biggest changes are in relation to the MABAC method, where one alternative can change its position by two ranks, while the application of other methods leads to a shift of rank by only one position in some cases.

A comparative analysis for the S-direction shows that the completely observed model has minor deviations in the ranks since, e.g., the first six positioned alternatives, ST17, ST7, ST14, ST10, ST8, and ST11, do not change their positions regardless of the applied method. When we observe individual rank deviations, there is a much different situation since there are deviations by three positions using the
ARA method when the ST12 alternative moves from the seventh to the tenth position. An even more drastic change relates to the application of the MABAC method and the ST12 alternative when it changes its place by five positions and comes in the 12th place. Regarding other alternatives and methods, changes in rankings compared to the initial results are practically negligible.

5.4. Calculation of $S C C$ and $S T_{D E V}$ for All Parts of the Sensitivity Analysis. This part of the sensitivity analysis refers to the calculation of the Spearman correlation coefficient for all previously applied approaches as well as the calculation of the standard deviation shown in Figure 10.

Observing the results shown in green, it can be noticed that the largest deviation of 2.251 is for alternative ST12 which changes its position by three to five places, and it refers to a comparative analysis for the S-direction. Then, the fourth alternative ST4 shows the largest subsequent deviation in ranks of 0.753 which results in a change by one to two positions. Alternative ST13 has a deviation of 0.548 because it changes its position by one place in the calculation of three methods (MABAC, WASPAS, and EDAS). Alternatives ST1, ST6, and ST16 show a deviation of 0.516 because they change by one position in two cases. Alternative ST5 has a deviation of 0.408 because only by applying the EDAS method, it changes its rank by one position. All remaining alternatives have a standard deviation of zero, which means that they retain their ranks by applying all methods. When it comes to deviations for the $\mathrm{N}$-direction, they are generally individually smaller because the largest standard deviation is 0.753 for ST1, ST4, and ST12, which means that there is a change of rank by two positions.

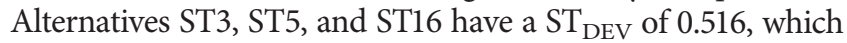
means a change of rank by one position. Other alternatives have deviations of 0.408 or zero. Observing the results obtained by applying different approaches to determine the weights of the criteria, larger deviations are noticed for both directions, in a range of $0-1.643$ for $\mathrm{S} 1$ and $0-1.517$ for N1.

Table 11 and Figures 11 and 12 show the Spearman and WS [36] correlation coefficient of all ranks obtained by different models and approaches through a whole sensitivity analysis.

When it comes to the ranks for a comparative analysis of the obtained results, the calculated SCC shows the following correlations: MARCOS and SAW methods have a complete correlation, SCC $=1.000$ for both directions. For the N-direction, the MARCOS and WASPAS methods have an almost full correlation of 0.998 resulting from the change of alternatives ST1 and ST12 by one position. ARAS with WASPAS and EDAS for the N-direction and ARAS with WASPAS and MABAC with EDAS for the S-direction have the same correlation value. SAW and ARAS for the N-direction have $S C C=0.995$. MARCOS with EDAS for the $\mathrm{N}$-direction and MABAC with WASPAS for the S-direction have the correlation value of 0.993 . ARAS and MABAC and WASPAS and EDAS for the S-direction have a correlation of 0.990. MABAC and WASPAS for the N-direction and ARAS and EDAS for the S-direction have SCC of 0.988. MARCOS 


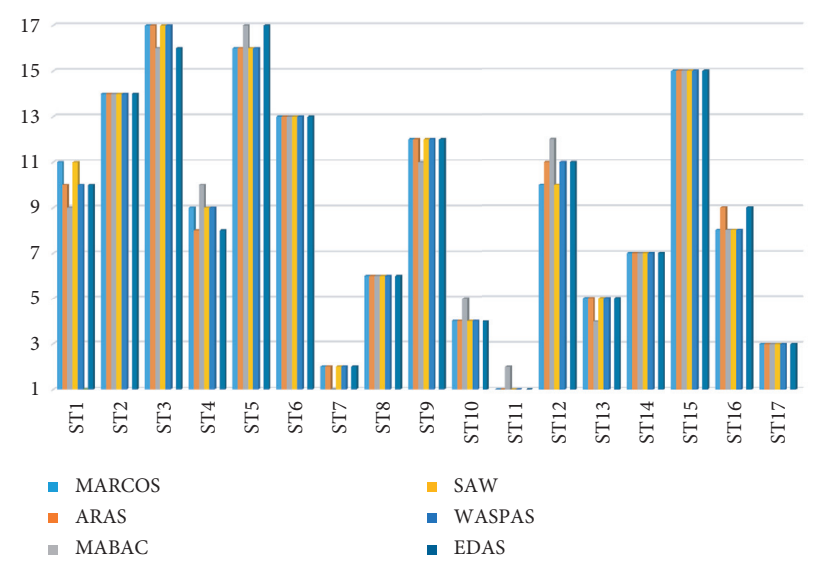

Figure 8: Comparison to other MCDM methods for the N-direction.

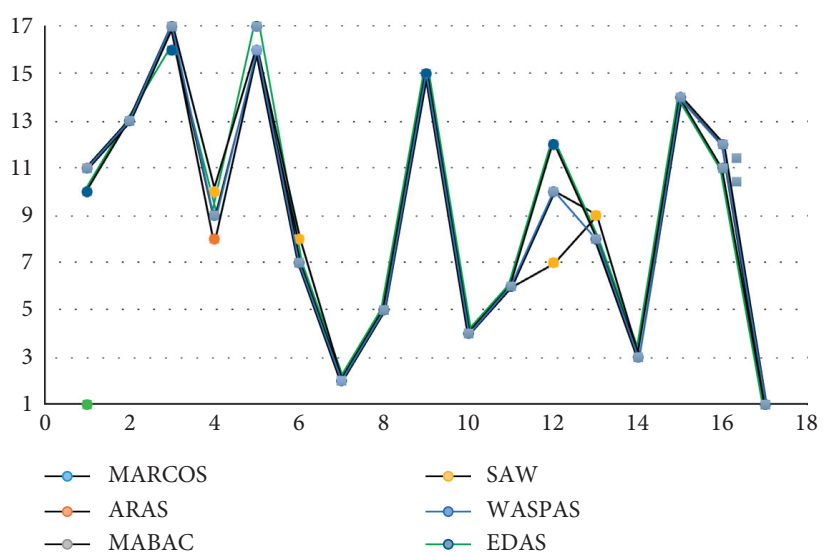

FIgure 9: Comparison to other MCDM methods for the S-direction.

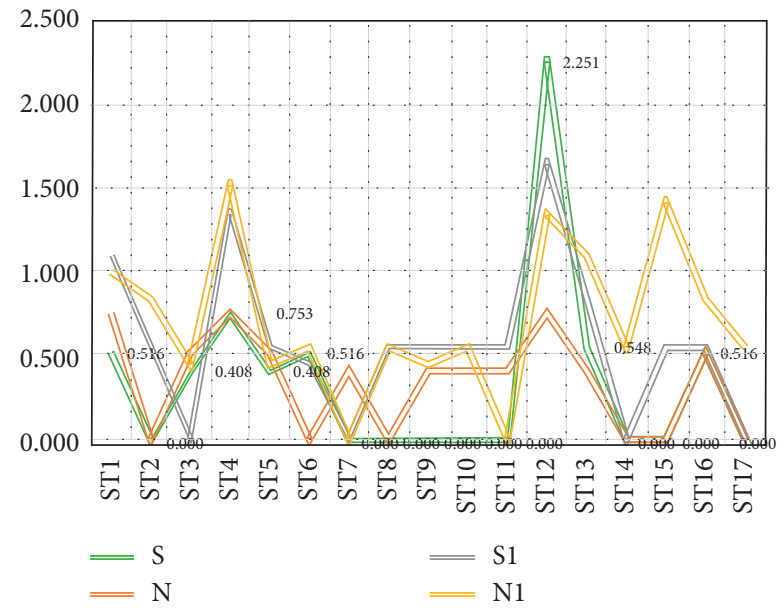

Figure 10: $\mathrm{ST}_{\mathrm{DEV}}$ for results obtained using all approaches. 
TABLE 11: SCC and WS coefficients for ranks obtained using various MCDM methods for ranking alternatives and determining criteria weights.

\begin{tabular}{|c|c|c|c|c|c|c|c|c|}
\hline $\mathrm{AV}$ & $\mathrm{N}$ & MARCOS & ARAS & MABAC & SAW & WASPAS & EDAS & AV \\
\hline 0.986 & MARCOS & 1.000 & 0.985 & 0.980 & 1.000 & 0.998 & 0.993 & 0.993 \\
\hline 1.000 & ARAS & 0.999 & 1.000 & 0.983 & 0.995 & 0.998 & 0.998 & 0.995 \\
\hline 0.962 & MABAC & 0.944 & 0.943 & 1.000 & 0.980 & 0.988 & 0.985 & 0.988 \\
\hline 0.986 & SAW & 1.000 & 0.999 & 0.944 & 1.000 & 0.998 & 0.993 & 0.997 \\
\hline 0.986 & WASPAS & 1.000 & 0.999 & 0.944 & 1.000 & 1.000 & 0.955 & 0.978 \\
\hline 0.999 & EDAS & 0.999 & 1.000 & 0.994 & 0.999 & 0.999 & 1.000 & 0.990 \\
\hline $\mathrm{AV}$ & $\mathrm{S}$ & MARCOS & ARAS & MABAC & SAW & WASPAS & EDAS & $\mathrm{AV}$ \\
\hline 1.000 & MARCOS & 1.000 & 0.983 & 0.963 & 1.000 & 0.985 & 0.961 & 0.982 \\
\hline 1.000 & ARAS & 0.999 & 1.000 & 0.990 & 0.983 & 0.998 & 0.988 & 0.992 \\
\hline 1.000 & MABAC & 0.999 & 1.000 & 1.000 & 0.963 & 0.993 & 0.998 & 0.988 \\
\hline 0.999 & SAW & 1.000 & 0.998 & 0.999 & 1.000 & 0.985 & 0.961 & 0.982 \\
\hline 1.000 & WASPAS & 0.999 & 1.000 & 1.000 & 0.999 & 1.000 & 0.990 & 0.995 \\
\hline 1.000 & EDAS & 0.999 & 1.000 & 1.000 & 0.999 & 1.000 & 1.000 & 0.988 \\
\hline & $\mathrm{N}$ & MARCOS & $\mathrm{CM}$ & Equal weights & \multicolumn{2}{|c|}{ DEA-1-MARCOS } & \multicolumn{2}{|c|}{ DEA-2-MARCOS } \\
\hline SCC & MARCOS & 1.000 & 0.966 & 0.973 & \multicolumn{2}{|c|}{0.988} & \multicolumn{2}{|c|}{0.980} \\
\hline WS & 1VARC & 1.000 & 0.999 & 0.999 & \multicolumn{2}{|c|}{0.998} & \multicolumn{2}{|c|}{0.998} \\
\hline & $S$ & MARCOS & $\mathrm{CM}$ & Equal weights & \multicolumn{2}{|c|}{ DEA-1-MARCOS } & \multicolumn{2}{|c|}{ DEA-2-MARCOS } \\
\hline SCC & MARCOS & 1.000 & 0.978 & 0.792 & \multicolumn{2}{|c|}{0.848} & \multicolumn{2}{|c|}{0.855} \\
\hline WS & МIAKCUS & 1.000 & 0.997 & 0.997 & \multicolumn{2}{|c|}{1.000} & \multicolumn{2}{|c|}{0.999} \\
\hline
\end{tabular}

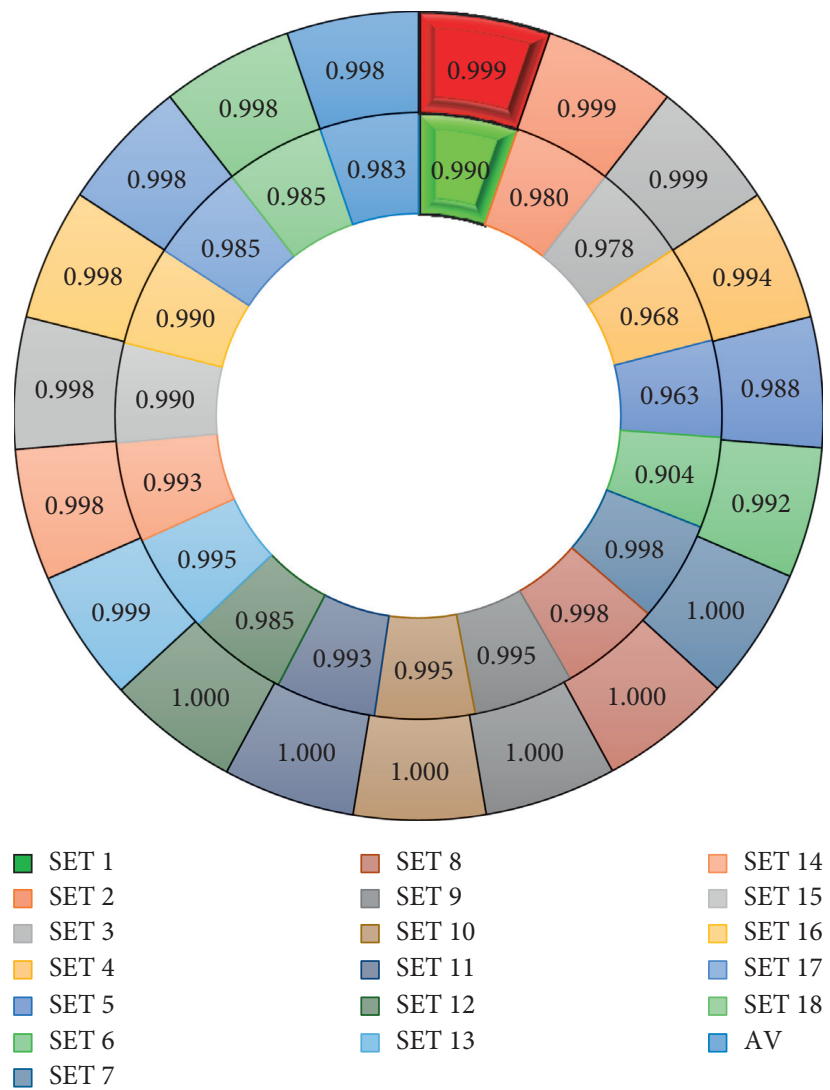

FIGURE 11: SCC and WS for ranks obtained with changing criteria weights for the N-direction. 


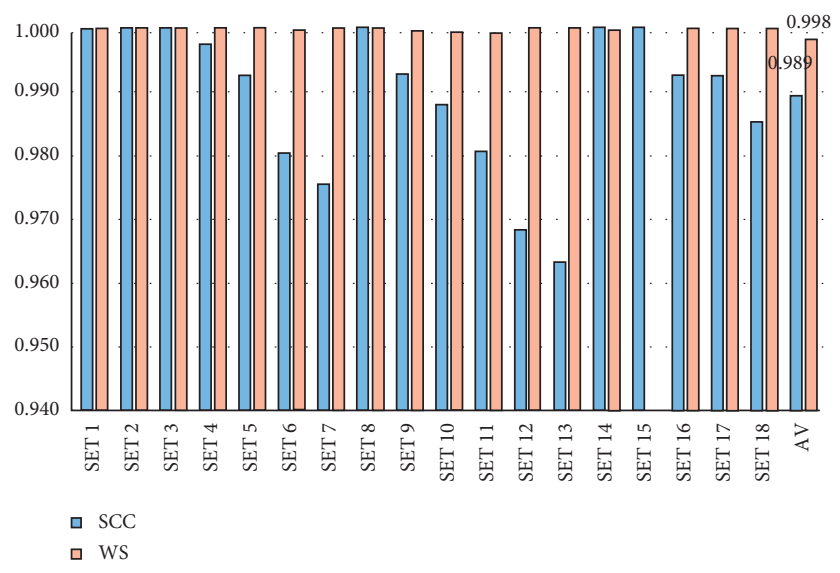

FIGURE 12: SCC and WS for ranks obtained with changing criteria weights for the S-direction.

has the lowest correlation with MABAC for both directions, 0.980 and 0.963 , respectively. Since the SAW method has a full correlation with MARCOS, it means that it has the same correlation with other models as the MARCOS method does. Taking into account the values of SCC according to Subotić et al. [37] and Muravev and Mijić [38], it can be concluded that the ranks of all alternatives according to a comparative analysis are very high, i.e., almost completely correlated. After additional calculation of WS coefficient (marked with grey color), it can be concluded that ranks have extremely high correlation.

Comparing the correlation values of the MARCOS method with approaches in which the weight values of the criteria have been calculated, it can be noticed that there is an extremely high correlation which ranges from 0.966 to 0.988 . MARCOS has the highest correlation with DEA-1-MARCOS with a value of 0.988 , while with DEA-2-MARCOS, it has a slightly lower correlation with a value of 0.980 . When calculating with equal criteria weights and inserting them in the MARCOS method, a correlation of 0.973 compared to the initial results is obtained. The results have the lowest correlation with comparisons by the CM model (0.966). These correlations refer to the $\mathrm{N}$-direction, while for the $\mathrm{S}$-direction, the correlation is quite lower and ranges from 0.848 to 0.978 .

Figure 11 shows the SCC and WS values for the ranks through 18 different scenarios in which the changes of criteria weights for the $\mathrm{N}$-direction were made. The average value of SCC is 0.983 , which means an extremely high correlation. The average value of WS is 0.998 , which means that ranks have almost full correlation. Although the model is sensitive to changes in the weights of the criteria and a change in ranks has been established based on the calculated SCC and WS, it can be concluded that changes in ranks are not large.

Figure 12 shows the SCC and WS values for the ranks through 18 different scenarios in which the changes of the criteria weights for the S-direction were made. The results show similarities with the $\mathrm{N}$-direction since the average correlation value, in this case, is 0.989 for SCC and 0.998 for WS coefficient, which is a very high correlation.

\section{Conclusion}

Implementing the developed model, the following results are obtained: alternative A11, i.e., Van Schalkwyk Street, is the safest with a value of 0.794 for the $\mathrm{N}$-direction. Volkspele Drive is the second in terms of safety, with Eric Rosendorf Street and Gardenia Avenue in the third and fourth place, respectively. Another alternative A13, i.e., Edeling Street, can be put into a group of safe streets comparing all alternatives. The group of most risky streets includes Wynand Mouton Drive, Paul Kruger Drive North, Benade Drive (N), Totius Street, and Paul Kruger Drive South whose values range from 0.341 to 0.421 . As already mentioned in the paper, data were collected for both directions, and the evaluation was performed accordingly, so it is evident that there are differences in terms of safety for individual streets. When it comes to the S-direction, the group of the five safest streets includes the following, respectively: Eric Rosendorf Street, Volkspele Drive, Stals Road, Gardenia Avenue, and Pellissier Drive. The group of least safe streets for the S-direction includes Wynand Mouton Drive, Paul Kruger Drive North, Paul Kruger Drive (E), and Benade Drive (N). Three streets that belong to the group of safe ones regardless of the direction are Eric Rosendorf Street, third and first positions, Volkspele Drive,second position for both directions, and Gardenia Avenue, which is in the fourth place. In terms of the most risky streets for both directions, Wynand Mouton Drive is in the last place, Paul Kruger Drive North in the 16th place, Benade Drive $(\mathrm{N})$ in the 15 th and 14th place, respectively, and Totius Street in the 14th and 13th place, respectively.

In order to validate the proposed model and the results obtained by its application, an extensive sensitivity analysis was performed consisting of (a) a reverse rank matrix, (b) a change of criterion weight in a dynamic environment, (c) an evaluation of alternatives based on individually obtained 
values of criteria weights, (d) a comparative analysis of obtained results with five other MCDM methods, (e) calculation of Spearman correlation coefficient (SCC) for all ranks obtained by applying different approaches, and (f) calculation of standard deviation of ranks obtained by applying different approaches. The validation results show that taking into account the large changes in the significance of the criteria, it can be concluded that changes in the ranks are not large, which was proven through the SCC calculation. Using DEA-1-MARCOS, i.e., DEA-2-MARCOS, and CM models, it can be concluded that the model is sensitive to the application of different approaches, but the results are highly correlated. A comparative analysis also confirmed the validity of the results, as well as the calculated SCC for all approaches and the calculated standard deviation.

Based on the findings from the model in terms of the ranking of vulnerable streets, the streets can be prioritized to take up road geometry and traffic-related intervention measures which could include applying the control measures to restrict the speed, optimal assignment of traffic volume during the peak hours, limiting the number of access streets, and the number of lanes, as well as providing adequate median width.

The scope of the study was confined to the development of the model based on road and traffic-related parameters, and the human and driver behaviour or weather-related parameters were not considered. However, the integration of such parameters to make the model more inclusive and holistic is the future scope of this research. However, at the current state, the model can enable assessment of the vulnerable streets adequately and prioritize them based on which traffic safety measures can be taken.

\section{Appendix}

\section{Determining Criteria Weights Using DEA-1 and DEA-2 Models}

An example of obtaining the values of criteria for DMU17-N is as follows:

$$
\begin{aligned}
& \operatorname{Max}=66 * w_{1}+5029 * w_{2}+6 * w_{3}+2 * w_{4}+4 * w_{5} \text {, } \\
& \left(71 * w_{1}+4611 * w_{2}+6.2 * w_{3}+2 * w_{4}+8 * w_{5}\right)-\left(16 * w_{6}\right)<=0 \text {, } \\
& \left(76 * w_{1}+8908 * w_{2}+6.5 * w_{3}+2 * w_{4}+8 * w_{5}\right)-\left(25 * w_{6}\right)<=0 \text {, } \\
& \left(79 * w_{1}+9938 * w_{2}+6.1 * w_{3}+1 * w_{4}+9 * w_{5}\right)-\left(32 * w_{6}\right)<=0 \text {, } \\
& \left(77 * w_{1}+8888 * w_{2}+6 * w_{3}+2 * w_{4}+8 * w_{5}\right)-\left(13 * w_{6}\right)<=0 \text {, } \\
& \left(72 * w_{1}+9285 * w_{2}+7.5 * w_{3}+2 * w_{4}+15 * w_{5}\right)-\left(32 * w_{6}\right)<=0 \text {, } \\
& \left(75 * w_{1}+7409 * w_{2}+7 * w_{3}+2 * w_{4}+11 * w_{5}\right)-\left(21 * w_{6}\right)<=0 \text {, } \\
& \left(58 * w_{1}+6040 * w_{2}+6 * w_{3}+2 * w_{4}+4 * w_{5}\right)-\left(8 * w_{6}\right)<=0 \text {, } \\
& \left(71 * w_{1}+5888 * w_{2}+7.5 * w_{3}+2 * w_{4}+4 * w_{5}\right)-\left(12 * w_{6}\right)<=0 \text {, } \\
& \left(73 * w_{1}+10055 * w_{2}+6.7 * w_{3}+2 * w_{4}+7 * w_{5}\right)-\left(22 * w_{6}\right)<=0 \text {, } \\
& \left(74 * w_{1}+5444 * w_{2}+6 * w_{3}+2 * w_{4}+4 * w_{5}\right)-\left(9 * w_{6}\right)<=0 ; \\
& \left(67 * w_{1}+3227 * w_{2}+4.3 * w_{3}+2 * w_{4}+4 * w_{5}\right)-\left(7 * w_{6}\right)<=0 \text {, } \\
& \left(81 * w_{1}+10016 * w_{2}+12 * w_{3}+3 * w_{4}+8 * w_{5}\right)-\left(33 * w_{6}\right)<=0 \text {, } \\
& \left(65 * w_{1}+7434 * w_{2}+6 * w_{3}+2 * w_{4}+4 * w_{5}\right)-\left(9 * w_{6}\right)<=0 \text {, } \\
& \left(67 * w_{1}+7267 * w_{2}+6 * w_{3}+2 * w_{4}+4 * w_{5}\right)-\left(11 * w_{6}\right)<=0 \text {, } \\
& \left(75 * w_{1}+8693 * w_{2}+9 * w_{3}+2 * w_{4}+11 * w_{5}\right)-\left(28 * w_{6}\right)<=0 \text {, } \\
& \left(70 * w_{1}+7047 * w_{2}+7.5 * w_{3}+2 * w_{4}+7 * w_{5}\right)-\left(16 * w_{6}\right)<=0 \text {, } \\
& \left(66 * w_{1}+5029 * w_{2}+6 * w_{3}+2 * w_{4}+4 * w_{5}\right)-\left(9 * w_{6}\right)<=0 \text {, } \\
& 9 * w_{6}=1 \text {, } \\
& w_{1}>=0, w_{2}>=0, w_{3}>=0, w_{4}>=0, w_{5}>=0, w_{6}>=0 \text {. }
\end{aligned}
$$




\section{Data Availability}

The data used to support the findings of this study are included within this article. However, the reader may contact the corresponding author for more details on the data.

\section{Conflicts of Interest}

The authors declare no conflicts of interest.

\section{References}

[1] J. W. Van Petegem and F. Wegman, "Analyzing road design risk factors for run-off-road crashes in The Netherlands with crash prediction models," Journal of Safety Research, vol. 49, pp. 121-127, 2014.

[2] E. Quaglietta, "A simulation-based approach for the optimal design of signalling block layout in railway networks," Simulation Modelling Practice and Theory, vol. 46, pp. 4-24, 2014.

[3] G. Yannis, A. Kopsacheili, A. Dragomanovits, and V. Petraki, "State-of-the-art review on multi-criteria decision-making in the transport sector," Journal of Traffic and Transportation Engineering (English Edition), vol. 7, no. 4, pp. 413-431, 2020.

[4] H.-W.. Wu, J. Zhen, and J. Zhang, "Urban rail transit operation safety evaluation based on an improved CRITIC method and cloud model," Journal of Rail Transport Planning \& Management, vol. 16, 2020.

[5] Z. Huang, R. Xu, and R. Yang, "Evaluation on equilibrium of passenger flow distribution on urban rail transit network," Journal of Transportation Systems Engineering Information Technology.vol. 18, no. 3, pp. 139-145, 2018.

[6] R. Liu, Z. Liu, H.-C. Liu, and H. Shi, "An improved alternative queuing method for occupational health and safety risk assessment and its application to construction excavation," Automation in Construction, vol. 126, Article ID 103672, 2021.

[7] R. Liu, X. Mou, and H.-C. Liu, "Occupational health and safety risk assessment based on combination weighting and uncertain linguistic information: method development and application to a construction project," IISE Transactions on Occupational Ergonomics and Human Factors, vol. 32, pp. 1-24, 2021.

[8] R. Bhavsar, A. Amin, and L. Zala, "Development of model for road crashes and identification of accident spots," International Journal of Intelligent Transportation Systems Research, vol. 19, no. 1, pp. 99-111, 2021.

[9] Q. Li, R. Liu, J. Zhao, and H.-C. Liu, "Passenger satisfaction evaluation of public transport using alternative queuing method under hesitant linguistic environment," Journal of Intelligent Transportation Systems, vol. 26, 2021.

[10] W. D. Cook, A. Kazakov, and B. N. Persaud, "Prioritizing highway accident sites: a data envelopment analysis model," Journal of the Operational Research Society, vol. 52, no. 3, pp. 303-309, 2001.

[11] J. Odeck, "Identifying traffic safety best practice: an application of DEA and Malmquist indices," Omega, vol. 34, no. 1, pp. 28-40, 2006.

[12] E. Hermans, T. Brijs, G. Wets, and K. Vanhoof, "Benchmarking road safety: lessons to learn from a data envelopment analysis," Accident Analysis \& Prevention, vol. 41, no. 1, pp. 174-182, 2009.

[13] F. H. Lotfi, R. Fallahnejad, and N. Navidi, "Ranking efficient units in DEA by using TOPSIS method," Applied Mathematical Sciences, vol. 5, pp. 805-815, 2011.
[14] S. Amelian, A. A. Shojaei, and S. M. R. Davoodi, "Road safety evaluation using data envelopment analysis case study: roads in provinces in Iran," International Journal of Vehicle Safety, vol. 9, no. 3, pp. 253-261, 2017.

[15] P.-T. Chang and J.-H. Lee, "A fuzzy DEA and knapsack formulation integrated model for project selection," Computers \& Operations Research, vol. 39, no. 1, pp. 112-125, 2012.

[16] A. Mohammadi, S. Rafiee, S. S. Mohtasebi, S. H. Mousavi Avval, and H. Rafiee, "Energy efficiency improvement and input cost saving in kiwifruit production using data envelopment analysis approach," Renewable Energy, vol. 36, no. 9, pp. 2573-2579, 2011.

[17] H.-T. Lin, "Personnel selection using analytic network process and fuzzy data envelopment analysis approaches," Computers \& Industrial Engineering, vol. 59, no. 4, pp. 937-944, 2010.

[18] Y. Chen, K. W. Li, H. Xu, and S. Liu, "A dea-topsis method for multiple criteria decision analysis in emergency management," Journal of Systems Science and Systems Engineering, vol. 18, no. 4, pp. 489-507, 2009.

[19] M. Stanković, Ž. Stević, D. Das, M. Subotić, and D. Pamučar, "A new fuzzy Marcos method for road traffic risk analysis," Mathematics, vol. 8, Article ID 457, 2020.

[20] D. Diakoulaki, G. Mavrotas, and L. Papayannakis, "Determining objective weights in multiple criteria problems: the CRITIC method," Computers \& Operations Research, vol. 22, no. 7, pp. 763-770, 1995.

[21] R. Rostamzadeh, M. K. Ghorabaee, K. Govindan, A. Esmaeili, and H. B. K. Nobar, "Evaluation of sustainable supply chain risk management using an integrated fuzzy TOPSIS- CRITIC approach," Journal of Cleaner Production, vol. 175, pp. 651669, 2018.

[22] T. Biswas, P. Chatterjee, and B. Choudhuri, "Selection of commercially available alternative passenger vehicle in automotive environment," Operational Research in Engineering Sciences: Theory and Applications, vol. 3, no. 1, pp. 16-27, 2020.

[23] A. Puška, I. Stojanović, and A. Maksimović, "Evaluation of sustainable rural tourism potential in Brcko District of Bosnia and Herzegovina using multi-criteria analysis," Operational Research in Engineering Sciences: Theory and Applications, vol. 2, no. 2, pp. 40-54, 2019.

[24] Ž. Stević, D. Pamučar, A. Puška, and P. Chatterjee, "Sustainable supplier selection in healthcare industries using a new MCDM method: measurement of alternatives and ranking according to COmpromise solution (MARCOS)," Computers \& Industrial Engineering, vol. 140, Article ID 106231, 2020.

[25] Ž. Stević and N. Brković, "A novel integrated FUCOMMARCOS model for evaluation of human resources in a transport company," Logistics, vol. 4, no. 1, p. 4, 2020.

[26] A. Puška, I. Stojanović, A. Maksimović, and N. Osmanović, "Evaluation software of project management used measurement of alternatives and ranking according to compromise solution (MARCOS) method," Operational Research in Engineering Sciences: Theory and Applications, vol. 3, no. 1, pp. 89-102, 2020.

[27] Y. Shen, E. Hermans, T. Brijs, G. Wets, and K. Vanhoof, "Road safety risk evaluation and target setting using data envelopment analysis and its extensions," Accident Analysis \& Prevention, vol. 48, pp. 430-441, 2012.

[28] I. Đalić, Ž. Stević, J. Ateljević, Z. Turskis, E. K. Zavadskas, and A. Mardani, "A novel integrated MCDM-SWOT-TOWS model for the strategic decision analysis in transportation company," Mechanical Engineering, vol. 32, 2021. 
[29] E. K. Zavadskas and Z. Turskis, "A new additive ratio assessment (ARAS) method in multicriteria decision-making," Technological and Economic Development of Economy, vol. 16, no. 2, pp. 159-172, 2010.

[30] D. Pamučar and G. Ćirović, "The selection of transport and handling resources in logistics centres using Multi-Attributive Border Approximation area Comparison (MABAC)," Expert Systems with Applications, vol. 42, no. 6, pp. 3016-3028, 2015.

[31] D. Bozanic, D. Tešić, and J. Kočić, "Multi-criteria FUCOM-Fuzzy MABAC model for the selection of location for construction of single-span bailey bridge," Decision Making: Applications in Management and Engineering, vol. 2, no. 1, pp. 132-146, 2019.

[32] K. R. McCrimmon, "Decision making among multiple-attribute alternatives: a survey and consolidation approach. RAND memorandum," 1968.

[33] E. K. Zavadskas, Z. Turskis, J. Antucheviciene, and A. Zakarevicius, "Optimization of weighted aggregated sum product assessment," Elektronika Ir Elektrotechnika, vol. 122, no. 6, pp. 3-6, 2012.

[34] G. Petrović, J. Mihajlović, Ž. Ćojbašić, M. Madić, and D. Marinković, "Comparison of three fuzzy MCDM methods for solving the supplier selection problem," Facta Universitatis, Series: Mechanical Engineering, vol. 17, no. 3, pp. 455-469, 2019.

[35] M. Keshavarz Ghorabaee, E. K. Zavadskas, L. Olfat, and Z. Turskis, "Multi-criteria inventory classification using a new method of evaluation based on distance from average solution (EDAS)," Informatica, vol. 26, no. 3, pp. 435-451, 2015.

[36] W. Sałabun and K. Urbaniak, "A new coefficient of rankings similarity in decision-making problems," in Proceedings of the International Conference on Computational Science, pp. 632645, Amsterdam, The Netherlands, June 2020.

[37] M. Subotić, B. Stević, B. Ristić, and S. Simić, "The selection of a location for potential roundabout construction-a case study of Doboj," Operational Research in Engineering Sciences: Theory and Applications, vol. 3, no. 1, pp. 41-56, 2020.

[38] D. Muravev and N. Mijic, "A novel integrated provider selection multicriteria model: the BWM-MABAC model," Decision Making: Applications in Management and Engineering, vol. 3, no. 1, pp. 60-78. 